NBER WORKING PAPER SERIES

\title{
DIAGNOSING MARKET POWER IN CALIFORNIA'S RESTRUCTURED WHOLESALE ELECTRICITY MARKET
}

\author{
Severin Borenstein \\ James Bushnell \\ Frank Wolak \\ Working Paper 7868 \\ http://www.nber.org/papers/w7868 \\ NATIONAL BUREAU OF ECONOMIC RESEARCH \\ 1050 Massachusetts Avenue \\ Cambridge, MA 02138 \\ September 2000
}

For helpful discussions and comments, we thank Carl Blumstein, Roger Bohn, Peter Cramton, Rob Gramlich, Paul Joskow, Alvin Klevorick, Christopher Knittel, Richard Maclay, Patrick McGuire, Catherine Wolfram, participants in the POWER Research Conference on Electricity Restructuring, and seminar participants at the Department of Justice and the NBER Summer Institute. Jun Ishii, Erin Mansur, Steve Puller, and Marshall Yan provided excellent research assistance. The views expressed herein are those of the authors and not necessarily those of the National Bureau of Economic Research.

(C) 2000 by Severin Borenstein, James Bushnell and Frank Wolak. All rights reserved. Short sections of text, not to exceed two paragraphs, may be quoted without explicit permission provided that full credit, including $\odot$ notice, is given to the source. 
Diagnosing Market Power in California's Restructured Wholesale Electricity Market

Severin Borenstein, James Bushnell, and Frank Wolak

NBER Working Paper No. 7868

September 2000

\begin{abstract}
Effective competition in wholesale electricity markets is a necessary feature of a successful electricity supply industry restructuring. We examine the degree of competition in the California wholesale electricity market during the period June 1998 to September 1999 by comparing the market prices with estimates of the prices that would have resulted if owners of instate fossil fuel generating facilities behaved as price takers. We find that there were significant departures from competitive pricing and that these departures are most pronounced during the highest demand periods, which tend to occur during the months of July through September. Through most of the winter and spring of 1999 there was little evidence of the exercise of market power. Overall, the exercise of market power raised the cost of power purchases by about $16 \%$ above the competitive level. Following the presentation of our methodology for computing the counterfactual price-taking market price, we describe why our calculation represents a lower bound on the extent of market power and why the observed market prices cannot by attributed to competitive peak-lead pricing.
\end{abstract}

Severin Borenstein

Haas School of Business

University of California

Berkeley, CA 94720

and University of California Energy Inst., and NBER

borenste@haas.berkeley.edu

Frank Wolak

Department of Economics

Stanford University

Stanford, CA 94305

and NBER

wolak@zia.stanford.edu
James Bushnell

University of California Energy Institute

2539 Channing Way

Berkeley, CA 94720

jimb@ieor.berkeley.edu 


\section{Introduction}

According to the United States Energy Information Administration, as of December 1999 all states were at least in the process of investigating electricity industry restructuring at the Public Utilities Commission (PUC) level or in the state legislature. Restructuring legislation has been enacted or a comprehensive regulatory order on industry restructuring has been issued in half of the states. As of the beginning of 2000, there are four regions of the country with independent system operators running spot markets for wholesale electricity-California, PJM (major parts of Pennsylvania, New Jersey, Maryland, Delaware, Virginia and the District of Columbia), New England, and New York. Several other regions of the country have recently received the approval of the Federal Energy Regulatory Commission to form an independent system operator (ISO).

A major rationale for electricity industry restructuring is to provide stronger incentives for efficient production and delivery of retail electricity than is possible under the vertically-integrated regulated monopoly regime. A deregulated market for electricity provides very strong incentives for least-cost production by a profit-maximizing generating firm. However, if firms possess market power, then they also have the ability to raise output prices above competitive levels. By constrast, the traditional monopoly regime and the associated regulatory process sets prices that allow the monopoly to recover all prudently incurred production costs. For this reason, even a profit-maximizing regulated firm has little incentive to produce in a minimum-cost manner. Strategic use of the regulatory price-setting process may enable the firm to earn a higher a level of profits by deviating from least-cost production. Consequently, the decision to restructure depends on which of these two imperfect worlds the decisionmaker believes will yield greater benefits to final consumers: (1) a competitive market with strong incentives for least-cost production but limited incentives for cost-reflective output prices, or (2) a regulated market with limited incentives for least-cost production but potentially more cost-reflective output prices.

Electricity industry restructuring is an evolutionary process. While the potential benefits are well-known, there is no universally agreed upon set of market rules for guaranteeing a successful industry restructuring. These markets are far too complex and involve far too many strategic agents for the market design process to be straightforward. Consequently, this transition can be most favorably described as a learning process informed by economic and policy analysis. All markets have implemented a number of market rule changes and market structure changes as flaws in the initial market design and market structure have been uncovered. In order to quantify the success of the restructuring process at any point

in time, it is necessary to have a reliable index of market performance. The purpose of this paper is derive such an index and apply it to the Calfornia electricity market. 
While market power has been studied and estimated in many industries, there has been little attention paid to the intertemporal variation in the ability to exercise market power. For most industries, those in which the good is storable, such intertemporal variation is necessarily small since inventories smooth the ability of firms exercise market power. In markets for non-storable goods, however, including electricity and most services, this is not possible. The problem is exacerbated in electricity because demand is very inelastic in the short run and supply becomes very inelastic as production approaches the generation capacity of producers. Recognizing the dynamics of market power is likely to be important in both determining its causes and crafting remedies as part of the evolving public policy towards electricity restructuring.

Luckily, in the California wholesale electricity market, due in part to its history of regulation, data exist on the hourly output of all generating units in the state and power flows into and out of the state. In addition, information collected on the technical characteristics of each California generating unit during the former regulated monopoly regime - specifically, the heat rate (the efficiency with which the fuel burned is turned into electricity) and variable operating and maintenance costs - allows very accurate estimation of generating unit-level variable costs. Finally, information on the bids submitted by nonstrategic market participants - those assumed to have no market power - can be used to construct counter-factual market prices in the absence of any market power.

The availability of the necessary inputs to our index is not unique to the California market, or even markets in the United States. Consequently, we believe that the benchmark, appropriately modified for the unique features of each market, should be regularly computed and monitored because it is an essential input to the ongoing restructuring process. The importance of regular calculation and monitoring of this index can be best understood by considering the size of the electricity supply industry in the US. The Energy Information Administration estimates that annual revenues from this industry in 1998 were $\$ 270$ billion. This implies that for every one percentage point that average retail prices are reduced approximately $\$ 2.7$ billion less is spent on electricity. Consequently, even minor market design improvements that limit the ability of generating unit owners to exercise market power and result in small reductions in retail electricity prices can provide significant benefits to consumers.

Because of the electricity industry's long history of regulation, there is little existing work that attempts to estimate the competitiveness of an electricity market based upon actual observed outcomes. Most of the work to date has instead relied upon market simulations that are based upon some form of oligopoly equilibrium. Green and Newbery 
(1992) apply the supply function equilibrium concept to the electricity market in England and Wales, while Schmalensee and Golub (1984) and Borenstein and Bushnell (1999) utilize the Cournot equilibrium assumption to simulate market outcomes for the continental U.S. and California markets, respectively. Borenstein, Bushnell, and Stoft (1998), Oren (1997), and Cardell, Hitt, and Hogan (1997) all utilize the Cournot assumption to analyze the impact of binding transmission constraints on strategic competition in the electricity industry.

Wolfram (1998 and 1999), Wolak and Patrick (1996), and Wolak (1999) are, to our knowledge, the only studies that estimate the actual levels of, rather than potential for, market power in the electricity industry. Wolfram (1999), using an approach similar to that applied here, estimates the extent to which one component of price paid to generators for energy - the system marginal price (SMP) - exceeds the marginal cost of the most expensive unit dispatched in the U.K. electricity market. She does this by reconstructing the cost curve of producers and comparing the resulting intersection of this marginal cost curve with demand to the actual SMP. Wolak and Patrick examine the impact of plant availability decisions by firms on the price paid to generators, which in the U.K. includes a payment for making capacity available and an uplift charge in addition to the SMP. They find evidence that the two largest generating firms profited considerably from declaring the output of some units unavailable at certain times. This lack of availability was correlated with the occurrence of market conditions that would make such a strategy particularly profitable.

In this paper, we analyze prices, generator variable costs, and actual production quantities to measure the degree to which California wholesale electricity prices exceeded competitive levels. We begin in section II by discussing the concept of market power in industries with limited production capacity, inelastic demand, and extermely costly storage. In particular, we point out the possible confusion of competitive peak-load pricing with the exercise of market power. We explain how these outcomes can be distinguished from one another and the importance of doing so. This section provides the theoretical foundation for the construction of our index of market performance.

In section III, we describe the most relevant details of the California electricity market and describe a general technique for estimating market power, given the institutional details of this market. In section IV, we describe our estimation technique in detail, addressing each component of the market and outlining the assumptions made in implementing the analysis. We try to take a conservative approach, interpreting the data in a way that would be likely to understate the degree of market power exercised. In section V, we present our 
results and discuss their significance in light of the assumptions made. We conclude in section VI.

\section{Market Power Analysis in the Electricity Industry}

Because the electricity industry has historically been dominated by vertically integrated regulated monopolies, policymakers and regulators have primarily been concerned with vertical market power. As such, the major policy initiatives with regards to electricity restructuring in the U.S. have focused on providing transmission access to potential entrants in the generation sector. The three regions that are farthest along in the this process - New England, Pennsylvania - New Jersey - Maryland, and California - have formed Independent System Operators (ISOs), which are charged with operating the transmission networks in a non-discriminatory manner.

In these and other electricity markets, focus has now shifted to the analysis of horizontal market power. In the regulatory arena, heavy emphasis has been placed on concentration measures, such as the Herfindahl-Hirschman index (HHI). Unfortunately, the electricity industry is characterized by a highly variable price-inelastic demand, significant short-run capacity constraints, and extremely costly storage. These factors combine to make market concentration a poor indicator of the potential for, or existence of, market power. ${ }^{1}$

Fortunately, because of its history as a regulated industry, a wealth of production cost and other data are available that allow for more direct analysis of the behavior of firms and the impacts of that behavior on market outcomes. Before discussing the specific analytic approaches, it is useful to contrast the behavior we might expect from a firm in this industry that is acting as price taker to that of a firm that is exercising market power.

\section{B. The Behavior of Price-Taking and Strategic Firms}

As in all industries, an electricity producing firm exercises market power when it reduces its output or raises the minimum price at which it is willing to sell output (its offer price) in order to change the market price. In the electricity industry, the marginal cost of production will include both the variable costs due to fuel and the other variable operating and maintenance costs.

1 See Borenstein, Bushnell, and Knittel (1999), for a more detailed discussion of the applicability of concentration measures to market power analysis in electricity markets and citations to regulatory decisions that have relied on concentration indices. 
Still, the cost of selling a unit of electricity can be greater than the simple production costs if the firm has an opportunity cost that is greater than its production cost, such as the revenue the firm would get from selling power or reserve capacity in a different location or market. We discuss these alternative opportunities below. Of course, a high price in an alternative market can reflect market power in that market, resulting in the transmittal of high prices across markets by the response of competitive suppliers.

The California electricity markets, like most electricity markets around the world, clear at a uniform price. Because a price-taking firm sells its output at the market price, and that market price is usually strictly above the marginal production cost of almost all the output it produces, price-taking firms can still cover their full costs of production, including their going-forward fixed costs of operation. If the industry marginal cost (i.e. competitive supply) function exhibits distinct steps - as is often thought to be the case in the electricity industry - then a competitive market equilibrium may be reached at which the price exceeds the marginal cost of even the last unit of output produced, but is still less than the marginal cost of producing one more unit of output. ${ }^{2}$ Similarly, if all units of production are in use, then the intersection of supply and demand can occur at a price above the marginal production cost of any unit. That is, in the absence of market power by any seller in the market, price may still exceed the marginal production costs of all facilities producing output in the market at that time. Price above marginal production cost of all operating plants is not in itself proof of market power. However, offering power at a price significantly above marginal production (or opportunity) cost, or failing to generate power that has a production cost below the market price, is an indication of the exercise of market power.

Some analysts of the electricity industry have raised the concern that price-taking behavior on the part of every firm is simply too strict of a standard to be used as a benchmark. They argue that it is unrealistic to think that no market power will exist, because some market power exists in most markets. We recognize this fact, and that a government's attempts to intervene to mitigate market power can be more costly to society than the market power itself. Nonetheless, there are many markets in which virtually no market power exists: most agricultural and natural resource markets, for instance. These industries are notable for producing virtually homogenous products and selling them over a large geographical area, characteristics that bear an important similarity to the electricity industry. Thus, while the presence of some market power should not be grounds

2 See Panzar (1976) for an investigation of these effects with marginal cost curves that are strictly upward sloping. 
for declaring restructuring of the electricity industry a failure or increasing the level of government intervention in the market, neither should it be accepted as inevitable based on observations from other industries.

In contrast to price-taking firms, a firm with market power can unilaterally influence the market price by withholding output at the margin or raising the price at which it is willing to sell this marginal output. Market power is enhanced when demand is relatively inelastic, as well as when the supply of other firms is inelastic, such as during peak production times in electricity markets. High storage costs also enhance market power, since inventories are not available as an alternative supply source if a firm tries to exercise market power. For this reason, electricity markets are more vulnerable to the exercise of market power than are other energy markets such as the one for gasoline.

Thus far, we have discussed only situations in which a firm unilaterally exercises market power. Antitrust law is most often concerned with collusive attempts to exercise market power. Unfortunately, many of the attributes that facilitate collusion are present in electricity markets: In most markets, firms play repeatedly, interacting on a daily basis, so there is opportunity to develop subtle communication and collusive strategies. The payoff from cheating on a collusive agreement may be limited due to capacity constraints on production, though for the same reason, the ability to punish defectors may be limited. Finally, the industry has fairly standardized production facilities, so homogeneous costs may make it easier for firms to reach tacit or explicit collusive behavior. All that said, we have not explored the question of tacit or explicit collusion among firms in the California market. Rather, in this paper we focus on market outcomes.

\section{Distinguishing Competition from Market Power}

It is important to stress that in both competitive markets and those with significant market power, prices can end up being higher than the marginal production costs of the last unit of power produced. In analyzing the electricity market in California, it is critical to be able to distinguish between competitive market pricing and pricing that results from the exercise of market power. Two indicators clearly distinguish these possible market results and each leads to a distinct estimation technique.

(1) In a competitive market, a firm is unable to take any action, including output decisions or offer prices, that will significantly affect the price in a market.

(2) The profit-maximizing response to (1) is that a competitive firm is always willing to sell a unit of output so long as its cost of selling that unit is less than the price it receives for that unit. Its offer price will always be its marginal cost, which will be the greater of 
its marginal production cost or its opportunity cost of selling the power elsewhere.

While these two indicators can be stated clearly, it is more difficult to apply them using the available data. The first indicator suggests a method of estimation that involves studying the specific actions of the various firms in the markets. In particular, one can examine, the bidding and output decisions of each unit or firm in the market to detect successful attempts to manipulate prices. This is the general approach used by Wolak and Patrick (1996), Wolfram (1998), Wolak (1999), Bohn, Klevorick, and Stalon (1998), and Bushnell and Wolak (1999).

The second indicator yields implications that can be tested by studying market-wide, rather than unit-specific behavior. As such, these tests are less vulnerable to the arguments of coincidence, bad luck, or ignorance that can be applied to the actions of a specific generator. In general, we test whether market prices are consistent with the hypothesis that the market as a whole is acting in a competitive manner. This approach is less informative about the specific manifestations of market power, but is effective for estimating its scope and severity, as well as identifying how departure from competition varies over time. This is the general approach used in Wolfram (1999), and the one that we adopt in this paper.

A potential drawback of this approach is that it captures all inefficiencies in the market, some of which may not be due to market power. If, for instance, the ISO systematically held low-cost generators out of production simply due to a faulty dispatch algorithm, that would impact the estimate of market power. During the period we study, the California market clearly still had a number of design flaws that contributed to inefficient dispatch and market pricing. For the great majority of these, however, the flaw would be fairly benign if firms acted as pure price takers, rather than exploiting these design flaws to affect the market price. Furthermore, we find that over substantial periods of time, prices did not significantly differ from our estimates of marginal cost, indicating that there were no systemic inefficiencies raising prices in all periods. Still, the estimates must be taken with the caveat that they include failures to achieve competitive market prices for reasons other than market power, including bad judgment and confusion on the part of some generators or market-making institutions.

\section{The Consequences of Market Power}

Due to the extreme short-run inelasticity of demand, market power in electricity markets will have little effect on consumption quantity or short-run allocative efficiency. If producing firms were symmetric, then there would also be little loss in productive efficiency either. As described below, however, generating companies in California vary 
markedly in their costs and generation capacity. Thus, the exercise of market power by one firm can lead to an inefficient reallocation of production among generating firms: a firm exercising market power will restrict its output so that its marginal cost is below price (and equal to its marginal revenue), while other firms that are price-taking will produce units of output for which its marginal cost is virtually equal to price. Thus, there will be inefficient production on a market-wide basis as more expensive, competitive, production is substituted for less expensive production owned by firms with market power. This is precisely what Wolak and Patrick (1996) describe as occurring in the U.K. market, where higher cost combined-cycle gas turbine generators owned by new entrants provide baseload power that could be supplied by coal-fired plants which are being withheld by the two large generators exercising market power.

In addition, several recent analyses have demonstrated that the exercise of market power in an electricity network can greatly increase the level of congestion on that network. ${ }^{3}$ This increased congestion impacts negatively both the efficiency and the reliability of the system. Market power can also lead firms to utilize their hydro-electric resources in ways that decrease overall economic efficiency. ${ }^{4}$

Lastly, it is important to remember that current electricity prices influence long-term decision-making in a way that can seriously impact the economy and efficient investment. While it has been pointed out that high prices should spur new investment and entry in electricity production, these investments may not be efficient if motivated by high prices caused by market power, which may indicate a need not for new capacity, but for the efficient use of existing capacity. Conversely, artificially high prices can lead some firms not to invest in productive enterprises that require the use of electricity.

Another important fact to consider when discussing market power in the California electricity market is that, during the 1998-2001 transition period, end-use consumers are insulated from energy price fluctuations by the Competition Transition Charge (CTC). The CTC is a mechanism that was implemented along with the restructuring of the industry in order to allow the incumbent utilities to recover their stranded generation costs. During the transition period, the vast majority of end-use consumers face fixed rate schedules that were also imposed along with the CTC. ${ }^{5}$ Thus, the CTC greatly lessens the elasticity of

3 See Cardell, Hitt and Hogan (1997), Bushnell (1999), Borenstein, Bushnell and Stoft (2000), and Joskow and Tirole (2000).

4 See Bushnell (1999).

5 Even "direct access" consumers, who buy energy from some source other than their incumbent utility, 
final consumer demand with respect to the price of energy.

Beyond the efficiency considerations, market power has potentially large and important redistributional effects. Analyzing these effects, however, is very difficult in most electricity markets, because most restructured markets have included various types of consumer protection - such as retail rate freezes - and many have also incorporated separate charges, like the CTC in California, which are intended to help utilities to cover the costs of stranded investment. When the CTC is considered, the exercise of market power by suppliers results at first appears to be a transfer of wealth from the incumbent utilities, rather than end-use consumers, to other suppliers. ${ }^{6}$ However, because of the way the CTC has been designed, higher energy prices are likely to delay its expiration, and thereby delay a significant drop in the rates of end-users. SDG\&E, in fact, ended its CTC in July 1999 and PG\&E and SCE may do so before the CTC cutoff date. In that case, by delaying the end of the CTC, the effect of market power exercised today in the California market is to transfer wealth from end users to non-utility generators. In fact, if the utility were confident that it would recover all of its stranded costs within the 4 year transition period, then that company would be largely indifferent to energy prices on the buy side. The generation side of these firms would clearly benefit from higher prices. The net impact on these firms of higher electricity prices therefore depends upon the firms' prospects for stranded asset recovery as well as the extent to which these firms were net buyers or sellers.

\section{The California Electricity Market}

The market for electricity in California is characterized by the repeated interaction of several firms and institutions. The two primary institutions are the California Power Exchange (PX) and the California Independent System Operator (ISO). The PX runs a day-ahead and hour-ahead market for energy utilizing a double auction format. ${ }^{7}$ Firms can and do submit both demand and supply bids. In the day-ahead market, which is by far the largest market run by the PX, firms may bid into the PX offers to supply or

are insulated from wholesale energy price fluctuations in the short-run by the CTC. This is because the stranded cost component paid by all consumers is calculated in a way that moves inversely to the energy price. The higher the energy price, the lower the CTC payment for that hour.

6 It is also worth noting that the incumbent utilities still sell a significant share of the energy produced in California, so the transfer occurs only on the power they buy from other generators.

7 The PX double auction accepts supply and demand bids from each market participant and sets a market clearing quantity at the intersection of the resulting aggregate supply and demand curves implied by all of these bids. Early in 1999, the PX changed its "hour-ahead" market (which actually closed three hours ahead of the operation hour) to a "day-of" market, which operates three times daily, each time for different designated hours of the day. 
consume power the following day for any or all of the 24 hourly markets. Although they were not originally envisioned as such, the PX markets are effectively financial, rather than physical, markets. As explained below, this is because firms can purchase or sell electricity in real time to change their day-ahead PX positions in what is essentially an energy spot market run by the ISO. ${ }^{8}$ In addition to the PX, other institutions, known as "scheduling coordinators," (SCs) can submit the results of completed wholesale energy transactions to the ISO. Each SC, including the PX, is formally required to submit a "balanced" schedule, i.e. one in which supply equals demand. ${ }^{9}$

The ISO is responsible for coordinating the usage of the transmission grid and ensuring that the cumulative transactions, or schedules, do not constitute a reliability risk. As the institution responsible for the real-time operation of the electric system, the ISO must also ensure that aggregate supply is continuously matched with aggregate demand. In doing so, the ISO operates an "imbalance energy" market, which is also commonly called the real-time energy market. In this market, additional generation is procured in the event of a supply shortfall, and generators are relieved of their obligation to provide power in the event that there is excess generation being supplied to grid. Like the PX, this market is run through a double auction process, although of slightly different format. Firms that deviate from their formal schedules are required to purchase (or sell) the amount of their shortfall (or surplus) on the imbalance energy market. ${ }^{10}$ During our sample period, no further penalties were assessed for deviating from an advance schedule. The imbalance energy market therefore serves as the de facto spot market for energy in California.

The ISO also operates markets for the acquisition of reserves and for the relief of constrained transmission interfaces. These reserves are purchased through a series of auctions that determine a uniform price for the capacity of each reserve purchased. Most of this reserve, or stand-by, capacity is also available to provide imbalance energy, and therefore will impact the spot price. A reserve unit would therefore earn a capacity payment for being available and, if called upon in real-time, the imbalance energy price, for actually providing energy.

8 The transaction costs of trading in the PX relative to the ISO, or other institutions is a source of considerable confusion. For the purposes of this discussion we consider these differences to be negligible relative to the costs of the underlying commodity, electrical energy.

9 In reality, schedules are seldom truly balanced due to the impact of transmission line losses. The protocols also allow for "inter-SC" trades, which permit an additional fudge factor on the balancing requirement.

10 The purchasing and selling is in fact done by the ISO itself, and accounts are settled through an ex-post adjustment. 
"Regulation", the most short-term reserve, is provided by generation that is equipped to respond automatically to voltage fluctuations. Due to the nature of this reserve service, and to metering limitations, generation capacity providing regulation reserves cannot set the imbalance energy price. It does earn the hourly imbalance energy price for all net energy supplied during each hour it is providing regulation. As we describe below, we therefore consider units providing regulation services to be "held-out" of the market.

\section{A. Market Structure}

The California electricity generation market at first glance appears relatively unconcentrated. The former dominant firms, Pacific Gas \& Electric (PG\&E) and Southern California Edison (SCE) divested the bulk of their gas-fired capacity in the first half of 1998 and most of the remainder in early 1999. SCE retained only a small proportion of its capacity not already covered under regulatory side agreements. These divestitures left the generation assets in California more or less evenly distributed between seven firms. The generation capacity of these firms during July 1998 and July 1999 is listed in Table 1.

As can be seen from Table 1, PG\&E was the largest generation company during the summer of 1998. The seemingly dominant position of PG\&E is offset to some extent by its other regulatory agreements. All of its nuclear generation in California, for instance, is treated under rate settlements separate from the PX market. Also the incumbent utilities in California were the largest buyers of electricity during this time period.

\section{B. Analyzing Market Power in California's Electricity Market}

Critical to studying market power in California is an understanding of the economic interactions between the multiple electricity markets in the state. Simply put, participants will move between markets in order to take advantage of higher (for sellers) or lower (for buyers) prices. For instance, if the ISO's real-time imbalance energy price were usually higher than the PX day-ahead price, then sellers who saw this would reduce the amount of power they sell in the PX and sell more in the ISO imbalance energy market. They would do this either by reducing the amount of power they bid into the PX or by raising the offer price on that power. At the same time, buyers would be moving in the opposite direction, trying to buy more in the PX and less in real time. Both of these attempts to arbitrage the PX/ISO price difference would have the effect of raising the PX price and lowering the ISO imbalance energy price, thereby eliminating the price differential.

For this reason, it is not useful to study the PX market, or any other of the California markets, in isolation. The strong forces of financial arbitrage mean that any change in one market that affects that market price will spill over into the other markets. For instance, 


\section{Table 1a: California Generation Companies (MW) July 1998 - Nameplate Capacity}

$\begin{array}{lrrr}\text { Firm } & \text { Fossil } & \text { Hydro } & \text { Nuclear } \\ \text { PG\&E } & 3700 & 5728 & 2160 \\ \text { SCE } & 1595 & 1002 & 2327 \\ \text { SDG\&E } & 1990 & 0 & 430 \\ \text { Duke } & 2639 & 0 & 0 \\ \text { AES/Williams } & 3921 & 0 & 0 \\ \text { Reliant } & 3698 & 0 & 0 \\ \text { Dynegy } & 1585 & 0 & 0 \\ \text { Other } & 322 & 0 & 0\end{array}$

\section{Table 1b: California Generation Companies (MW) July 1999 - Nameplate Capacity}

$\begin{array}{lrrr}\text { Firm } & \text { Fossil } & \text { Hydro } & \text { Nuclear } \\ \text { PG\&E } & 570 & 5728 & 2160 \\ \text { SCE } & 1595 & 1002 & 2327 \\ \text { Duke } & 3343 & 0 & 0 \\ \text { AES/Williams } & 3921 & 0 & 0 \\ \text { Reliant } & 3698 & 0 & 0 \\ \text { Dynegy } & 2831 & 0 & 0 \\ \text { Southern } & 3130 & 0 & 0 \\ \text { Other } & 322 & 0 & 430\end{array}$

if a generator selling power in the PX market were to suffer an outage that prevented it from offering power in the PX market, this would raise the price in the PX, but it would also attract sellers from other markets and encourage PX buyers to buy elsewhere until the PX price was once again in line with the price in other California electricity markets.

Table 2 contains sample means of the monthly zonal PX price and real time energy price for the North of Path 15 (NP15) and South of Path 15 (SP15) zones. To investigate the arbitrage relationship between the ISO and PX, we also compute the sample mean of the hourly difference between the day-ahead zonal PX price and ISO imbalance energy zonal price for these two congestion zones. Though one market has a significantly higher price than the other in certain months, there is no significant difference in many months and, overall, there is no consistent pattern of the PX price being higher or lower than the 
Table 2: Average Zonal Energy Prices (\$/MWh)

Month

June 1998

July 1998

August 1998

September 1998

October 1998

November 1998

December 1998

January 1999

February 1999

March 1999

April 1999

May 1999

June 1999

July 1999

August 1999

September 1999
North of Path 15 (NP15)

\author{
PX
}

12.25

32.51

38.80

33.97

27.85

27.24

30.42

21.79

19.19

19.74

24.25

24.07

24.15

32.01

34.65

38.98
Mean

ISO

8.38

26.08

45.39

40.77

35.24

30.57

29.58

19.79

18.98

20.09

25.42

19.66

21.87

22.22

36.34

40.97
Std Dev

PX-ISO

3.86

6.43

$-6.59$

$-6.80$

$-7.39$

$-3.34$

0.84

2.00

0.21

$-0.35$

$-1.17$

4.41

2.28

9.78

$-1.68$

$-2.00$
9.68

29.57

36.92

30.26

9.96

6.68

20.37

5.27

5.57

11.61

18.91

14.31

23.96

32.09

35.48

31.64

Month

June 1998

July 1998

August 1998

September 1998

October 1998

November 1998

December 1998

January 1999

February 1999

March 1999

April 1999

May 1999

June 1999

July 1999

August 1999

September 1999

South of Path 15 (SP15)

$\begin{array}{rrrr}\text { PX } & \text { ISO } & \begin{array}{r}\text { Mean } \\ \text { PX-ISO }\end{array} & \begin{array}{r}\text { Std Dev } \\ \text { PX-ISO }\end{array} \\ 12.34 & 8.38 & 3.95 & 9.42 \\ 33.14 & 25.98 & 7.16 & 30.25 \\ 39.96 & 43.53 & -3.56 & 36.96 \\ 33.24 & 35.13 & -1.88 & 29.68 \\ 23.92 & 27.78 & -3.85 & 11.28 \\ 22.91 & 24.08 & -1.16 & 7.84 \\ 26.73 & 26.13 & 0.60 & 17.96 \\ 21.09 & 19.50 & 1.59 & 5.53 \\ 19.19 & 18.98 & 0.21 & 5.56 \\ 19.48 & 20.09 & -0.61 & 11.61 \\ 24.32 & 25.42 & -1.10 & 18.97 \\ 24.06 & 19.66 & 4.40 & 14.30 \\ 23.93 & 21.87 & 2.06 & 24.12 \\ 29.91 & 22.22 & 7.68 & 32.01 \\ 32.80 & 34.47 & -1.67 & 34.11 \\ 29.28 & 33.09 & -3.81 & 32.83\end{array}$


ISO price. ${ }^{11}$

This interaction of the different California electricity markets means that we must study the entire California energy market in order to analyze market power in the state. For this reason, in the analysis below we look at the entire generation in the ISO/PX service area regardless of whether the power from a generating plant is being sold through the ISO, the PX, or some other SC. This recognition of the California power market as being effectively an integrated market due to strong arbitrage forces yields two other important insights.

Monoposony Power: The California market has a few very large buyers of electricity, the large utility distribution companies (UDCs). This has lead to concern that buyers may be able to exercise monopsony buying power in the energy market, thereby depressing the price of electricity. When California is viewed as a series of closely integrated electricity markets, however, it appears much less likely that monopsony power will be a significant issue.

It is well understood that in a single market, a buyer with completely inelastic demand cannot exercise monopsony power, regardless of the quantity it is purchasing. The UDCs have a demand that is virtually perfectly price inelastic: they are required to provide the amount of power that their customers demand and those customers do not see the hourly PX or ISO energy prices, only a fixed retail price per $\mathrm{kWh}$ that does not vary with either the PX or ISO price for that hour. Moreover, the vast majority of the interruptible power supply contracts held by the incumbent utilities during the period we study did not allow curtailment of power for economic reasons such as high PX or real-time prices.

Yet, an analysis of a single market within California, such as the PX day-ahead market, might lead one to think that a buyer could, by reducing its purchases in the PX, consistently lower the PX price and reduce its power purchase costs. But this is a fallacy based on a failure to recognize the interactions of the markets. If a large buyer reduced its power purchases in the PX day-ahead market, it would have to make up the difference in the PX day-of or ISO imbalance energy market (or by buying through some other SC if that were allowed), since end-use consumers' total purchases are insensitive to price. If the buyer purchased more power in the imbalance energy market and less in the PX day-ahead market - and no other participants changed their behavior - then the imbalance energy price would rise above the PX day ahead price. This would set up a profitable opportunity

11 Borenstein, Bushnell, Knittel, and Wolfram (2000) test for price convergence between the ISO and PX markets. 
for sellers in the PX to switch to selling in the ISO's imbalance energy market and buyers in the imbalance energy market to buy more in the PX day-ahead market. Such movement would occur until the prices in the two markets were once again equalized. ${ }^{12}$ This would occur where the aggregate of the supply curves in the day-ahead and real-time imbalance energy markets intersects the aggregate of the demand curves in the two markets. The result would be no change in the market price in either market and no change in the power purchasing cost to the UDC.

Thus, in equilibrium, a pure buyer with an inelastic total demand for power cannot exercise market power in the California electricity market by moving its purchases between the various available venues for trading power. ${ }^{13}$ To the extent that a UDC owns its own generation, however, it may be able to exercise monopsony power by reducing net purchases. If an IOU in California had some production capacity that has cost above the market clearing price, it could drive down the market price by bidding in that capacity at below its true marginal cost. It is possible that the reduced price on the energy the IOU does buy could produce greater savings than the loss it would take from running a unit when price is below its MC. If this did occur during the time frame we study in California, it would tend to reduce our estimates of market power. Note, however, that this would require the UDC to have generation with costs near the market-clearing price. Because of the divestiture of the majority of gas-fired units owned by SCE and SDG\&E before the summer of 1998, PG\&E is the only UDC with any significant ability to do this. ${ }^{14}$

Price Caps: The integrated view of these markets also helps to understand how price caps affect the market. In analyzing price caps, however, the order in which the markets clear becomes important. This is because a buyer or seller who doesn't transact in one market can transact in a later market, but not vice versa. Put differently, a player in these markets can credibly commit to transact in the last market, but has a much more difficult time credibly committing to transact in any market that clears earlier.

12 In actuality, they would have to be equal in expectation. A seller in the PX would have to expect that it would earn the same price, on average, by waiting and selling in the imbalance energy market.

13 One could argue that this could still happen if the buyer surprises the market occasionally by moving its purchases from one market to another. It is not clear that such behavior would be expected to lower the buyer's total energy cost. The reason is that once sellers realized the buyer was doing this they would attempt to figure out when it would happen and move their supply in accordance with the expected demand shifts. Sometimes they would be wrong and would move supply out of the PX when no demand shift was occurring, thereby raising the UDC's total energy cost.

14 As explained earlier, it also is not at all clear that the UDCs would have the financial incentive to exercise monopsony power to lower wholesale power prices if they believed that they would fully recover their stranded investments through the CTC before the recovery deadline. 
The effect of this is easily illustrated in a slightly simplified version of the California market. Assume that the only markets available are the day-ahead PX market and the ISO's imbalance energy market. Consider a case in which, absent any price caps, both markets would clear at a price of $\$ 300 / \mathrm{MWh}$. This high price could result under competition because supply available to the market is unusually low due to unforeseen outages or demand is unusually high due to weather or other factors. It could also occur as the result of market power being exercised. ${ }^{15}$ Now assume that a price cap of $\$ 250$ is imposed in the PX market. Clearly no supplier would be interested in selling its power in the PX, seeing that they expect to earn a price of $\$ 300$ in the imbalance market. Consumers really have no choice in the matter, because suppliers know that whatever power is not purchased in the PX must be bought in the imbalance market. Therefore, a price cap in the PX would be completely ineffective absent a similar cap in the imbalance market. The only effect of a price cap in the PX would be to move transactions out of the PX and into the ISO's imbalance energy market.

Contrast this with the situation during our sample period, in which there was a price cap of $\$ 250 /$ MWh on imbalance energy prices, but a much higher cap of $\$ 2500 / \mathrm{MWh}$ on PX prices. In that case, it is buyers who prefer the imbalance energy market whenever prices are expected to exceed $\$ 250$ in the PX. As such, we would expect to never see prices above $\$ 250$ in either market. To prevent prices of $\$ 250$ in the PX, buyers simply bid demand curves into the PX that have zero demand at $\$ 250$, because they know that is the maximum price at which they can purchase all of their demand at in the imbalance energy market. Sellers would prefer to sell at the higher PX price, but given the bidding behavior of demanders, the price that clears the PX will never be greater than $\$ 250$. In fact, during the period we study, the highest unrestricted PX price never exceeded $\$ 225 / \mathrm{MWh}$. This discussion demonstrates that, because of the sequential nature of the markets, the only price cap that will significantly affect the price actually paid for power is the one on the last market to clear.

Opportunity Costs and Market Power: When analyzing the extent of market power in the energy market, we must consider the effect of prices in other markets in which the same suppliers compete. Those generators that are eligible can earn capacity payments for providing ancillary services, as well as energy payments for generating in real time, if they bid successfully into one of the ancillary services markets. Ancillary services therefore represent an alternative use of much of the generation capacity in California. It is therefore

15 It should be clear by now that the supply and demand we are speaking of are the aggregates across all markets, since arbitrage would determine how much is actually transacted in each of the markets. 
necessary to consider the interaction between the energy and ancillary services markets.

It is important to recognize that the pool of suppliers available to ancillary services markets is very similar to that available to the energy markets. The main difference is that some generators are physically unable to provide certain ancillary services. Thus there are fewer potential suppliers for some ancillary services than there are for energy. We therefore would expect that the energy market would be at least as competitive as the ancillary services markets, and probably more so. It follows that price-cost margins would be at least as great if not greater in ancillary services markets than in energy markets. In fact the ancillary services markets, for a variety of reasons, appear to have been significantly less competitive than the energy market during the time period of our study. ${ }^{16}$

The other prominent opportunity for the usage of California generation is the supply of power to neighboring regions. Higher prices for energy outside of California could produce a result in which all generators within California were able to earn prices above their marginal cost, even if they behaved as price takers. For this to be the case, the California ISO region would have to be a net exporter of power. During our sample period, such conditions arose only in a total of five hours, four in June 1998 and one in October 1998, out of the 11,686 hours in the sample. Even in these hours, the maximum net quantity of energy exported out of the ISO control area in any hour was a modest $540 \mathrm{MWh}$. Therefore, export opportunities outside of the ISO are unlikely to explain the price-cost margins detailed below.

\section{Measuring Market Power in California's Electricity Market}

The fundamental measure of market power is the margin between price and the marginal cost of production. As discussed above, if no firm were exercising market power, then all units with marginal costs that are below the market price would be operating. Even in a market in which some firms exercise considerable market power, the marginal unit that is operating could have a marginal cost that is equal to the price. When a firm with market power reduces output from its plants or, equivalently, raises its offer price for its output, its production is usually replaced by other, more expensive generation that may be owned by non-strategic firms. Thus, although the marginal cost of the most expensive unit operating at a given time may indeed equal the market price, market power would still be present if there were other generators with costs below that price that are choosing not to supply power.

16 See Wolak, Nordhaus, and Shapiro (1998) 
In estimating a price-cost margin in this paper, we therefore must estimate what the marginal cost of serving a given level of demand would be if all firms were behaving as price takers. Unlike most industries, there is enough information available about the costs of the generators to directly estimate the price-cost margin. That is not to say that this measurement is without difficulty. There are many factors that add complexity to the task of estimating the marginal cost of electricity production at a given output level. In addition, one must be careful in defining the market clearing quantity upon which these marginal cost estimates will be based. In the following subsections we describe the assumptions and data used for generating estimates of the marginal cost of supplying electrical energy in California.

\section{A. Market Clearing Prices and Quantities}

As described above, the California electricity market in fact consists of several parallel and overlapping markets. Fortunately, our assessment of the overall degree of market power is simplified by the fact that most sellers and buyers are free to participate in any of these markets. With this fluidity of market participants across markets, we would expect that the market clearing prices from each of these markets to be equal in expectation. ${ }^{17}$

Given that generation and distribution firms, as well as other power traders, can arbitrage the expected price of energy across these commodity markets, the price of energy in one market should be an accurate signal of its price in the other markets. In the calculations presented below, we rely upon the unconstrained PX day-ahead energy price as our estimate of energy prices in any given hour. We chose to rely upon the PX unconstrained price because it represents the market conditions most closely replicated in our estimates of marginal costs. In particular, we do not consider the costs of transmission congestion or local reliability constraints in our estimates of the marginal cost of serving a given demand. The PX unconstrained price is also derived by matching aggregate supply with aggregate demand without considering these constraints. The resulting market clearing price therefore reflects an outcome that would occur in the absence of transmission constraints, just as our cost calculations reflect the outcome in a market in which all producers are price takers and there are no transmission constraints. ${ }^{18}$

17 One might be concerned that this arbitrage would not hold in light of the requirement, established in the legislation facilitating the restructuring of the electricity industry in California, that the three investor-owned utilities buy all of their energy from the PX. Given the financial nature of the PX market, the full meaning of this requirement is somewhat ambiguous. More importantly, it appears that the wording of the law has not prevented the IOUs (and others) from arbitraging energy prices across the PX and ISO energy markets.

18 We would like to emphasize again that we use the PX price as representative of the prices in all 
The interaction of these energy markets also permits us, indeed requires us, to use the systemwide aggregate demand as the market clearing quantity upon which we base our marginal cost estimates. This level therefore includes consumption from the PX, other SCs, and any "imbalance energy" demand that is provided through the ISO imbalance energy market. Consumption from all of these markets is in fact metered by the ISO, which in turn allocates charges amongst SCs during an ex-post settlement process. We are therefore able to obtain these aggregate market clearing quantities from the ISO settlement data.

The acquisition of reserves by the ISO also requires discussion here. Since the ISO is effectively purchasing considerable extra capacity for the provision of reserves, it might seem appropriate to consider these reserve quantities as part of the market clearing demand level. However, with the exception of regulation reserve, as described below, all other reserves are normally available to meet real-time energy needs if scheduled generation is not sufficient to supply market demand. ${ }^{19}$ Thus, the real-time energy price is still set by the interaction of real-time energy demand - including quantities supplied by reserve capacity - and all of the generators that can provide real-time supply. Therefore, we consider the real-time energy demand in each hour to be the quantity that must be supplied and capacity selected for reserve services to be part of the capacity that can meet that demand and, as such, to be part of our aggregate marginal cost curve.

The most responsive form of reserve is regulation. Units providing regulation services are required to automatically adjust their output levels in a way that allows the ISO to continuously balance supply and demand. Unlike the other forms of reserve, regulation capacity, is, in a way, held out of the imbalance energy market and its capacity could therefore be considered to be unavailable for additional supply. For this reason we add the upward regulation reserve requirement, which at times reaches $11 \%$ of demand, to the market clearing quantity for the purposes of finding the overall marginal cost of supply. ${ }^{20}$

California electricity markets. This is not a study of the PX market and the market power we find is not limited to the PX market. It is the amount present in all California electricity markets.

19 Due to reliability concerns, the ISO at times has not utilized spinning and non-spinning reserves for the provision of imbalance energy (see Wolak, Nordhaus, and Shapiro, 1998). The conditions under which this occurs are somewhat irregular and difficult to predict. For the purposes of this analysis we have assumed that these forms of reserve are utilized for the provision of imbalance energy.

20 Regulation reserve is procured for both an upward (increasing) and downward (decreasing) range of capacity. The ISO needs to be able to continuously increase and decrease the output levels of certain units in order to balance the system. Since the generation units that are providing downward regulation are, by definition, producing energy, the capacity providing downward regulation should not be considered to be held out of the energy market. Note also that by adding regulation needs to the market demand, we are implicitly assuming that all regulation requirements are met by generation 


\section{B. Marginal Cost of Thermal Generating Units}

In estimating the marginal cost of production for an efficient market, we use the fuel costs of each thermal generating unit as well as the variable operating and maintenance $(\mathrm{O} \& \mathrm{M})$ cost of each thermal unit. The marginal cost of each thermal unit is calculated by using its average heat rate multiplied by fuel cost and adding an estimate of variable O\&M to that product. These cost estimates are detailed in Appendix A. Figure 1 illustrates the aggregate marginal cost curve for thermal generation plants located in the ISO control area that are not considered to be "must-take" resources (see below). ${ }^{21}$

The supply curve illustrated in Figure 1 does not include any adjustments for "forced outages." Generation unit forced (as opposed to scheduled) outages have traditionally been treated as random, independent events that, at any given moment, may occur according to a probability specified by that unit's forced outage factor. In our analysis, each generation unit, $i$, is assigned a constant marginal cost $m c_{i}$ - reflecting that unit's average heat rate, fuel price, and its variable O\&M cost - as well as a maximum output capacity, $c p_{i}$. Each unit also has a forced outage factor, $f o f_{i}$, which represents the probability of an unplanned outage in any given hour. Because of concern that fuel costs for in-state fossil units might differ depending on access to fuel sources and changing market conditions during the period we study, we used weekly average prices of natural gas at a number of different locations in the state (see Appendix A).

Because the aggregate marginal cost curve is convex, estimating aggregate marginal cost using the expected capacity of each unit, $c_{a} p_{i} * f o f_{i}$, would understate the actual expected cost at any given output level. ${ }^{22}$ We therefore simulate the marginal cost curve that accounts for forced outages using Monte Carlo simulation methods. If the generation units $i=1, \ldots, N$ are ordered according to increasing marginal cost, the aggregate marginal cost curve produced by the $j_{t h}$ iteration of this simulation, $C_{j}(q)$, is the marginal cost of the $k_{t h}$ cheapest generating unit, where $k$ is determined by

units with costs below the market clearing price. To the extent that some units providing regulation would not be economic at the market price, this assumption will tend to bias downward an estimate of market power.

21 Our estimates assume that the rated capacities of the plants are strictly binding constraints. It has been pointed out to us that the plants can be run above rated capacity, but at the cost of increased wear and more frequent maintenance. If we incorporated this factor - about which there seems to be very little detailed information - it would shift rightward the industry supply curve. The implication would be that the industry marginal cost we calculate is higher than the actual industry marginal cost, which would bias downward estimates of market power.

22 For any convex function $C(q)$, of a random variable $q$, we have, by Jensen's inequality, $\mathrm{E}(C(q)) \geq$ $C(\mathrm{E}(q))$. 


$$
k=\arg \min x \mid \sum_{i=1}^{x} I(i) * \operatorname{cap}_{i} \geq q .
$$

where $I(i)$ is an indicator variable that takes the value of 1 with probability of $1-f_{o} f_{i}$, and 0 otherwise. For each hour, the Monte Carlo simulation of each unit's outage probability is repeated 100 times. In other words, for each iteration, the availability of each unit is based upon a random draw that is performed independently for each unit according to that unit's forced outage factor. The marginal cost at a given quantity for that iteration is then the marginal cost of the last available unit necessary to meet that quantity given the unavailability of those units that have randomly suffered forced outages in that iteration of the simulation. If, during a given iteration, the residual demand exceeded available capacity, the price was set to $\$ 250 / \mathrm{MWh}$, the maximum allowed under the ISO imbalance energy price cap during our sample period. Note that the PX price never hit this level, so such outcomes were counted as "negative market power" outcomes in the analysis. Thus, these outcomes are not driving, and if anything are reducing, our finding of market power.

We did not adjust the output of generation units for scheduled outages. This is because the scheduling, and duration of planned outages for maintenance and other activities is itself a strategic decision. Wolak and Patrick (1996) present evidence that the timing of such outages was extremely profitable for certain firms in the U.K. electricity market. It would therefore be inappropriate to treat such decisions as random events. Since we find market power in the summer months - high demand periods in California in which the utilities have historically avoided scheduled maintenance on most generation - it is unlikely that scheduled maintenance could explain these results in any case. ${ }^{23}$ We would expect scheduled maintenance to take place in the autumn, winter and spring months, which is the time period over which we find little, if any, market power.

The operation of generation units of course entails other costs in addition to the fuel and short-run operating expenses. ${ }^{24}$ It is clear that sunk costs, such as capital costs, and periodic fixed maintenance expenses should not be included in any estimate of shortrun marginal cost. More difficult are the impacts of various unit-commitment costs and constraints, such as the cost of starting up a plant, the maximum rates at which a plant's output have be ramped up and down, and the minimum time periods for which a plant can

23 Scheduled maintenance on must-take resources, such as nuclear plants, and reservoir energy sources was accounted for under the procedures outlined in the following sections.

24 We do not account explicitly for emission costs from these thermal generators, but they are not a significant factor: based upon an assumption of $\$ 400 /$ ton of emission (which is greater than the average cost during our sample period), they were about $\$ 1$ million dollars for the period we study. 
be on or off. These constraints create non-convexities in the production cost functions of firms. For a generating unit that is not operating, these costs are clearly not sunk. On the other hand, it is not at all obvious that it is optimal for a price-taking profit-maximizing firm to pro-rate such costs into its supply bids. In fact, it is relatively easy to construct examples where it would clearly not be optimal to do so. ${ }^{25}$ For the time being, we do not attempt to capture directly the impacts of these constraints on our cost estimates, although we do discuss interpretations in light of these non-convexities.

\section{Hydro, Geothermal and 'Must-take' Generation}

Conventional thermal generation units, most of them located in California and fueled by natural gas, constitute most of the potential supply that, at any given time, is "in play" in the energy commodity markets. This is not to say that these units constitute the bulk of the energy, or even capacity available to the California electricity market. Due to preexisting regulatory, environmental, and economic commitments, a large percentage of the electrical energy consumed in California comes from generation sources that are effectively taken before any of the conventional thermal units described above. For our purposes, these generation sources can be divided into two categories: reservoir energy sources such as hydro and geothermal, and generators whose output has been pre-committed under regulatory must-take agreements.

Must-take Generation: Accounting for the impact of the must-take generation is the most straightforward. Must-take generation is composed primarily of the nuclear generation owned by the three incumbent California investor-owned utilities and independent generation providing power under a series of PURPA-based long-term contracts. Since all of the output of these generation units is covered under regulatory side agreements, the energy commodity markets in California are effectively setting market clearing prices for the residual demand that is left over after accounting for the output of these units. ${ }^{26}$

In this paper we focus on the severity of market power in the energy commodity mar-

25 For example, consider a generator who estimates that it will be 'in' the market for six hours on a given day and bids into the market in each hour at a level equal to its fuel costs plus $1 / 6$ of its start-up cost. Now imagine a market outcome where the price in one hour rises well above this bid level, but in subsequent hours remains at a level above the unit's fuel costs, but below the sum of its fuel cost and pro-rated start-up. This unit thereby has committed to operate in one hour, but is 'out' of the market in subsequent hours, even though it could have cleared an operating profit at market clearing prices.

26 In practice, this is accomplished by a requirement that all must-take generation bid its output into the PX at a zero price. This produces the same result as shifting leftward the demand that is bid into the PX by an equivalent amount. 
kets. Therefore, we must consider the marginal cost of supplying the residual demand that remains after the supply from must-take units, and the market-clearing price of meeting that demand. We do this by removing the must-take energy that is produced in each hour from the market-clearing quantity and removing the must-take generators from the set of units available to meet that quantity. Fortunately, the output of must-take generation is separately identified in the ISO settlement data and can therefore be accounted for relatively easily.

Hydro and Geothermal Generation: Hydroelectric and geothermal generation compose another major source of energy production in California's electricity market. For the purposes of market analysis, these generation sources pose a more difficult problem than must-take generation. These resources, which produce energy from a reservoir of potential energy, have variable production costs that are negligible. Since the amount of potential energy in the reservoir is usually limited, however, the production of energy from such a resource entails a foregone opportunity to produce that energy at some other time. Therefore, while the physical production costs from these resources is very low, the opportunity costs of such production can be significant. Operating constraints, such as minimum and maximum limits on the instantaneous output of these units, also impact the opportunity costs of production.

Because of their flexibility, hydro resources are extremely valuable assets for a number of reasons. Their ability to quickly adjust output levels make hydro resources very useful "load following" ("load" being the industry terminology for quantity demanded) and reserve resources. For the moment, we will focus on the primary advantage of a reservoir energy resource: the ability to store energy over time. A price-taking firm with hydro resources would try to allocate as much output to the highest price period as is possible, given the hydro units' operating constraints. If enough hydro energy and capacity were available, price-taking firms would be able to shave price peaks, leaving the price of power constant across all time periods.

Instead of equalizing prices across time, a firm with market power that controlled reservoir resources would attempt to equalize its marginal revenue across those time periods. Operating constraints would most likely limit a firm's ability to fully equalize its marginal revenue across all periods, but to the extent possible it would move hydro production from hours in which it has low marginal revenue to hours in which it has high marginal revenue. For this reason, a strategic firm can find it profitable to allocate relatively more hydro 
production to off-peak periods than to peak periods than would a price-taking firm. ${ }^{27}$

Unfortunately, detecting such a strategic use of reservoir energy sources is much more difficult than estimating the market power exercised by owners of thermal generators whose marginal costs are more easily understood. The hydro and geothermal resources in the state of California are all currently owned by the incumbent investor-owned utilities. Because of various factors, including environmental constraints and the fact that these utilities are large buyers of power, the ability and incentives of these firms to exercise market power are somewhat muted relative to those of the new generation owners who have no final customers to serve.

For these reasons, in this study we assume that there is no strategic use of hydro or geothermal resources. In other words, we take the actual, observed output of these resources as the level that would be produced by a price-taking firm acting in a perfectly competitive market. This is a conservative assumption, one that will produce downward biased estimates of market power, for two reasons. First, the observed output levels will differ from those that minimize costs if the output of these resources had actually been used in a strategic fashion. Second, the output of these resources may differ from their least-cost usage due to the fact that the actual output reflects the response of hydro firms to the exercise of market power by other firms. If the actual hydro and geothermal output schedules differ from the cost-minimizing schedules for either of these reasons, our estimates of the marginal cost of serving load under a competitive dispatch will be biased upward overall and our estimates of market power will be biased downward.

In practice, this assumption means that, in constructing our estimate of the marginal cost of meeting load in any given hour, we apply the observed production of hydro and geothermal resources for each hour and then calculate the marginal cost of satisfying the remaining demand with the state's thermal resources. Figure 2 illustrates this calculation. The thermal cost curve in this calculation is static. The point at which this curve intercepts demand in each hour is adjusted according to the amount of must-take and reservoir energy production in that given hour.

\section{Imports and Exports}

One of the most difficult aspects of estimating the marginal cost of meeting total demand in the ISO system is accounting for imports and exports between the ISO control area and other control areas. Unlike must-take generation, many imports and exports

27 See Bushnell, 1998, for a more detailed analysis of the strategic use of hydro resources. 
are not a result of pre-existing contractual arrangements. Unlike hydro generation, we cannot automatically assume that imports and exports would always be inframarginal. Although we can observe the net amount of power entering or leaving the ISO system at each interface point, we do not have data on the value (or opportunity cost) of that power outside California, nor on the cost of transmitting power to the interface point.

If the power market outside of California were perfectly competitive, then the marginal generator that is importing into California would, absent transmission constraints, have a marginal cost about equal to the market price in California. When market power is exercised within California, this would mean that, in an effort to drive up price, some in-state generators are withdrawing (or raising the offer price on) their less expensive generation and allowing more-expensive imported power to be substituted for it. In other words, in the absence of market power, we would see less imports. This means that the cost of serving the demand that remains after the competitive level of imports is netted out would be higher than the cost of serving the demand that remains after the true level of imports is adjusted for. ${ }^{28}$

Figure 3 illustrates a hypothetical marginal cost curve of the in-state generation, excluding must-take and reservoir energy resources. The market demand is $q_{t o t}$, and the observed price is $p_{p x}$. At a price of $p_{p x}$, we see imports of $q_{i m p}\left(=q_{t o t}-q_{r}\right)$ that shift the remaining demand to the left to a quantity $q_{r}$. If the price were instead set at the competitive price of $p^{*}$, we would see imports at some level less than or equal to those seen at $p_{p x}$. This would shift the residual in-state demand curve to a quantity $q_{r}^{*}$. Thus, in order to estimate the price-taking outcome in the market, we need to make some assumption with regard to the elasticity of import supply.

Estimating the Elasticity of Import Supply: One of the primary responsibilities of the California ISO is to ensure the reliable usage of the system's transmission network. This requires that the ISO sometimes operate a market for rationing transmission capacity when its use is oversubscribed. This market is implemented through the use of schedule "adjustment" bids, which are submitted by scheduling coordinators to the ISO along with their preferred day-ahead schedules.

Scheduling coordinators submit their preferred import quantities and the ISO verifies

28 Capacity constraints on both the transmission interfaces into California and the production capacity of non-Californian producers complicate this intuition somewhat. If such a capacity constraint were binding at the observed California market clearing price, then the marginal production cost of imports would most likely be below this market clearing price. In such a circumstance, one cannot say with certainty that a perfectly competitive price within California would yield less imports. 
that these imports do not exceed transmission capacity limits. If these proposed imports are feasible, no further adjustments are required. In the event that the net of proposed import and export schedules does exceed transmission capacity on some interface, the ISO initiates a process of congestion relief by adjusting schedules according to their adjustment bids. $^{29}$ Adjustment bids establish, for each schedule coordinator, a willingness-to-pay for transmission usage. Schedules are adjusted according to these values of transmission usage, starting at the lowest value, until the congestion along the interface is relieved. A uniform price for transmission usage, paid by all SCs using the interface, is set at the last, or highest value of transmission usage bid by an SC whose usage was curtailed. ${ }^{30}$

The adjustment bid process is intended to allocate scarce transmission capacity to its most valued uses, and to price that capacity based upon those values. Adjustment bids take the form of supply and demand curves located on either side of a congested transmission interface. A price-taking SC that is importing power into California, for example, would submit as adjustment bids its cost of imported power on one side of the interface, and its resale value of that power on the other side. The difference between the import cost and resale value is the schedule coordinator's value of using the transmission interface. If this value is less than the transmission usage charge, the $\mathrm{SC}$ would want its schedule to be curtailed. If the transaction value is still greater than the transmission usage charge, then the SC would want the scheduled import to proceed. If the quantity of imports at the unconstrained PX price, when combined with imports from other SCs, exceeds the import capacity, then import quantities from this zone are adjusted downward according to their adjustment bids. This adjustment continues until the import quantity is feasible. At this point, only the imports that are profitable, even with the transmission charge, remain.

The adjustment bids provide information about the elasticity of imports. Adjustment bids reveal the willingness-to-supply of imported energy at each interface over a wide range of import quantities, not just at the observed import quantity. By aggregating the import adjustment bids over all transmission interfaces and over all schedule coordinators, we can establish an upper bound on the elasticity of import supply. Let the import supply curve of schedule coordinator $s c$ at import zone $z$ be the net of its preferred import quantity and all of its incremental and decremental adjustment bids into California from $z$.

29 Before turning to adjustment bids, there is an iterative round in which schedule coordinators are allowed to modify their preferred schedules voluntarily, possibly through agreements with other schedule coordinators. If a transmission interface is still constrained after this iteration, the ISO relieves it directly through the use of adjustment bids.

30 For a more detailed description of the transmission congestion relief process, see Bushnell and Oren (1997). 


$$
q_{z}^{s c}(p)=q_{z}^{s c, i n i t}+\sum_{\hat{p}<p} q_{z}^{s c, i n c}(\hat{p})-\sum_{\hat{p}>p} q_{z}^{s c, d e c}(\hat{p}) .
$$

In other words, the ideal level of imports from $s c$ at $z$ at a price of $p$, would be the sum of its scheduled imports, which are independent of price, and the amount of extra supply it is willing to provide at a price at or below $p$ less the amount of supply it does not want to produce at price $p$. The aggregate import curve into the California ISO system for any hour can be estimated as by summing the value of $q_{z}^{s c}(p)$ over all interfaces and SCs:

$$
q_{i m p}(p)=\sum_{s c} \sum_{z} q_{z}^{s c}(p)
$$

This aggregation constitutes an upper bound because the ISO is in practice prevented from substituting import adjustments across individual schedule coordinators or across transmission interfaces, so that the actual import supply curve will yield significantly steeper function of price than the curve constructed as described above. The ISO will only act in the event that the initial schedules indicate that congestion will arise, even though the adjustment bids may indicate a potential Pareto improving import adjustment. Thus, while our aggregate import supply curve assumes that all imports from all locations are perfect substitutes, and that these imports are priced at marginal cost, reality falls short of this level of import efficiency. Our aggregate import adjustment supply curve therefore will overstate the responsiveness of imports to a change in the California energy price. Thus, this understates the level of imports that would result from price-taking behavior within California, and will overstate the marginal cost of meeting California demand, and therefore lower our estimates of the extent of market power.

\section{E. Calculating Cost Increase Relative to Competitive Outcome}

Utilizing the assumptions outlined in the previous sections, we estimated the perfectly competitive market price in the California energy markets for each hour of market operation from June 1998 through September 1999. The residual market demand $q_{r}$, to be met by thermal units within the ISO system, is estimated to be

$$
q_{r}^{t}(p)=q_{t o t}^{t}+q_{r e g}^{t}-q_{m t}^{t}-q_{r s v}^{t}-q_{i m p}^{t}(p) .
$$

where, $q_{t o t}^{t}$ is the actual ISO metered generation and imports for hour $t$. This number therefore includes generation scheduled through all energy markets associated with the 
ISO control area, including the PX, ISO imbalance energy market, and other SCs. $q_{r e g}^{t}$ represents the addition to demand due to the need for capacity dedicated to regulation. The quantities $q_{m t}^{t}$ and $q_{r s v}^{t}$ represent the amount of energy produced by must-take generation and by resevoir (hydro and geothermal) generation, respectively. These quantities are all treated as price inelastic. The level of imported energy, $q_{i m p}^{t}(p)$ is adjusted by the market clearing price, as described above.

We make 100 thermal generation cost estimates, each reflecting a combination of independent Monte Carlo draws for the outage of a generation unit, for each hour. For each of these draws from the system-wide marginal cost curves we compute the intersection of this marginal cost curve with the residual market demand curve $q_{r}^{t}(p)$. This yields an estimated marginal cost and an instate market-clearing quantity $q_{r j}^{t}$ for Monte Carlo draw j. We denote the marginal cost associated with this quantity as $C_{j}^{t}$. Note that for each of the 100 draws from the aggregate marginal cost curve, we obtain different values of marginal cost and the instate net market-clearing quantity. Consequently, we index each of these values by $\mathrm{j}$, to denote the number of the draw. We can then compute an estimate of the expected value of the marginal cost of meeting the instate demand that results from price-taking behavior by instate generators as:

$$
\bar{C}^{t}=\frac{\sum_{j=1}^{100}\left(C_{j}^{t}\right)}{100} .
$$

Note that there are cases in which $P_{p x}^{t}-\bar{C}^{t}$ is negative in our simulations. Absent an attempt at predatory pricing, firms will not actually be willing to sell power at prices below their true economic short-run marginal costs. In other words, prices will not be below the perfectly competitive price. Nonetheless, during some hours, particularly June 1998 and during the winter and spring of 1999, PX prices were below our estimates of the perfectly competitive market price. At least three factors contribute to these outcomes.

First, our cost estimates can exceed the actual marginal cost because we do not consider the dynamic effects of unit commitment constraints, such as start-up costs, ramping rates and minimum down times. These constraints can create opportunity costs of shutting down units that, in essence, lower the true marginal cost of operating that plant. Of course these same constraints also can create opportunity costs that, at other times, raise the true marginal cost. This is one reason why we include the negative mark-ups in our results; we did not want to exclude the off-peak impact of these constraints on our cost-estimates, since there is an opposite effect on our estimates during peak-hours.

Second, cost information for generating units are not exact data on which all parties 
agree. In some cases, our estimates of a unit's marginal cost could be slightly too high and in others slightly too low. Therefore we include negative price-cost differences in order to prevent truncating the effect of data uncertainty on our cost-estimates.

Third, and probably most importantly, our calculations do not control separately for the output levels of reliability must-run (RMR) generation, since we focus on the PX unconstrained price. Some generation units have been declared must-run for local grid reliability under certain conditions. These generators get separate non-market payments when they are called under the RMR contracts they have signed with the ISO. RMR units are not dispatched as part of the system. Because they are held out and paid a different price, the resulting price in the PX can be below the marginal cost to the system if the power provided by RMR units were instead provided as part of the full dispatch of the system. In fact, due to the high level of RMR calls by the ISO during the time period we study, particularly the spring, it is possible that no other thermal generation was economic during some time periods. In those cases, the highest cost units selling in the PX could be hydro or out-of-state coal plants, either of which have lower marginal cost than any of the thermal plants we examine. However, these periods are likely to occur when the PX price is extremely low, not extremely high. In such cases, import energy with costs below those of in-state thermal generation (such as out-of-state hydro) could be the marginal generation, and the actual PX price could be lower than the marginal costs of any of the thermal units we have examined. Because we don't account for the RMR units, our estimates could still indicate that a thermal unit is marginal and its cost is the system marginal cost, so our estimated system marginal cost would be above the actual PX price due to unaccounted-for RMR calls. ${ }^{31}$

If the estimated MC is above the PX price for either of the first two reasons, then it seems that the most accurate estimate of market power would come from including the "negative market power" outcomes in our calculations. However, the total startup costs for the thermal units in California is probably less than $\$ 30$ million during our sample period, less than $4 \%$ of the effects we find. ${ }^{32}$ In addition, there are other reasons to think that startup costs explain only a minor part of the deviations from marginal cost pricing.

31 This implies that neglecting RMR calls could underestimate market power. In addition, it appears from preliminary evidence that the implementation of RMR agreements has exacerbated some of the local market power problems that they were designed to mitigate. See Wolak, Nordhaus, and Shapiro (1998).

32 For most of the units in our thermal cost curve, these costs had been estimated for inclusion in the contract payments for RMR performance. Total annual costs for start-ups of RMR units were about $\$ 17$ million. 
First, the units that turn on to meet peak demand during the summer have little or no startup costs, so the impact at the times we find the greatest market power is likely to be low. Second, we find virtually no margins in the winter, when there are more plant startup costs in aggregate than during summer months. ${ }^{33}$

Likewise, it is unlikely that much of the negative market power outcomes could be the result of cost data errors. Many PX prices in June, for instance, were well below the costs that anyone has claimed for operation of thermal generating units. ${ }^{34}$ Thus, it is most likely that the cost estimates that exceed the PX price occur because there were no thermal generating units that were economic to run at the time. Only thermal units running under RMR contracts were active. In that case, the marginal cost of the system, and thus the market price, is being set by much cheaper out-of-state coal plants, by nuclear plants, or by hydro or geothermal plants. If this is the case, then the proper treatment would be to truncate the results, resetting any finding of "negative market power" to set marginal cost equal to price. Still, in order to avoid biasing the results in favor of finding market power, we don't truncate the negative outcomes in the primary results we report.

\section{Results}

We computed the perfectly competitive price each hour for the months of June 1998 through September 1999 using the algorithm described above for computing the expected perfectly competitive price for each hour.

Based upon the import adjustment bids, the import supply curve is quite inelastic. The average hourly reduction in imports from the observed level at the PX price versus the level at our estimate of marginal cost was $5.3 \%$, with a standard deviation of $8.1 \%$. The maximum hourly predicted reduction due to price-taking behavior was $51 \%$. Imports were not significantly more price elastic during peak periods. During hours in which the PX price was above $\$ 70 / \mathrm{MWH}$ the average import reduction that would arise from pricetaking behavior in California was estimated to be $11.8 \%$. These results illustrate a very price inelastic import supply response over a wide range of prices below observed PX prices.

33 Additionally, if marginal cost functions turn upward smoothly around the rated capacity, rather than having a strict L-shape, the typical argument that a competitive plant would bid its startup costs for the "single hour" it would run are incorrect. In that case, even the last plant turned on would run for many hours because it would be replacing higher-cost output from other plants that would otherwise be producing along the steepest parts of their MC curves.

34 If we were to ignore any "negative market power" outcomes for prices below, say, $\$ 18 /$ MWh, virtually all of the "negative market power" effects would be eliminated. 
The added cost of energy due to departures from a competitive market, $\Delta T C$, is calculated by taking the difference between the PX price and our estimate of marginal cost and multiplying it by the total ISO metered generation less the must-take energy for that hour. ${ }^{35}$ That is, for hour $t$,

$$
\Delta T C^{t}=\left[p_{p x}^{t}-\bar{C}^{t}\right] *\left[q_{t o t}^{t}-q_{m t}^{t}\right]
$$

where $\bar{C}^{t}$ is expected marginal cost in period t. This expectation is taken with respect to the distribution of generating unit outages. Must-take energy is subtracted from the total load because this power is paid for under pre-existing contractual or regulatory agreements. Power sold through SCs other than the PX (and through the ISO itself) is included in this calculation since, as explained above, it is assumed that price differences across SCs would be arbitraged away. Higher prices for PX power therefore imply higher prices for power from other SCs, as well as the imbalance energy market. In fact, many bilateral power contracts are indexed to the PX price. To compute our index we also need the total cost of total ISO load less must-take energy purchased at the PX price, which is

$$
T C^{t}=\left[p_{p x}^{t}\right] *\left[q_{t o t}^{t}-q_{m t}^{t}\right]
$$

to get an indication of how large $\Delta T C^{t}$ is relative to the total energy costs.

Our measure of market performance for index set $\mathrm{S}$ is equal to

$$
M P(S)=\frac{\sum_{t \in S} \Delta T C^{t}}{\sum_{t \in S} T C^{t}}
$$

where $\mathrm{S}$ is a pre-selected set of hours during our sample period. For example, $\mathrm{S}$ could be the set of all hours in one month during the sample, the set of all hours in sample between 8 am and $8 \mathrm{pm}$, or the set of all hours in our sample period. For the index set $\mathrm{S}$, our measure gives the average increased cost of providing electricity during all hours in that set. For example, $\mathrm{MP}(\mathrm{S})$, for $\mathrm{S}$ equal all hours in our sample period, gives the average increased cost of wholesale electricity due to prices that deviate from the competitive benchmark.

Defining $\mathrm{MP}(\mathrm{S})$ in this manner is consistent with the view reflected in our competitive benchmark Monte Carlo simulation that the observed market price is conditional on a realization from the joint distribution of generating unit outages. To reflect this fact, let

35 By taking the observed quantity as the market demand, we are, for the reasons discussed earlier, implicitly assuming that demand is price inelastic. 
$\hat{p}_{p x}^{t}$ denote observed PX price for hour $\mathrm{t}$ and $E\left(\hat{p}_{p x}^{t}\right)$ the expectation of this magnitude with respect to the joint distribution of generating unit outages. Unlike the counterfactual case assuming price-taking behavior, we cannot draw from the distribution of generating unit outages and compute a distribution of market prices that reflect the current level of market power. This would require a model for the strategic interaction of among players in the California market. However, by defining $\mathrm{MP}(\mathrm{S})$ as shown in equation (8), we can take advantage of the law of large numbers to prove that our measure is a consistent estimate of the average cost increase. To show this, re-write the index as:

$$
M P(S)=\frac{1 / \operatorname{Card}(S) \sum_{t \in S}\left[\hat{p}_{p x}^{t}-\bar{C}^{t}\right] *\left[q_{t o t}^{t}-q_{m t}^{t}\right]}{1 / \operatorname{Card}(S) \sum_{t \in S} \hat{p}_{p x}^{t} *\left[q_{t o t}^{t}-q_{m t}^{t}\right]},
$$

where $\operatorname{Card}(\mathrm{S})$ is the cardinality or number of elements (hours) in the set S. For sets $\mathrm{S}$ with a large number of elements, the index is approximately equal to

$$
M P(S)=\frac{\sum_{t \in S}\left[E\left(\hat{p}_{p x}^{t}\right)-\bar{C}^{t}\right] *\left[q_{t o t}^{t}-q_{m t}^{t}\right]}{\sum_{t \in S} E\left(\hat{p}_{p x}^{t}\right) *\left[q_{t o t}^{t}-q_{m t}^{t}\right]},
$$

which is equal to the ratio of the expected cost increase relative to the perfectly competitive benchmark due to the current level of market power and market imperfections divided by the expected cost of purchasing electricity under current market conditions.

Figures 4 through 10 show the hourly PX price and estimated marginal cost for July through September of each year as well as for January 1999, a typical low demand month. Table 4 reports the PX price, estimated marginal cost, and the added cost of power due to prices that exceeded marginal cost for each month in the sample period. As is evident from Table 4, June 1998 produced very idiosyncratic results, with an average PX price considerably below our estimate of marginal cost. The market was only in its third full month of operation at this time, and many of the thermal generation units were at this time going through a process of ownership transfer and regulatory approval. As described above, the use of reliability must-run contracts, which provide thermal units with subsidies beyond the market price, was also widespread during June. For these reasons, we believe the market results from June 1998 do not provide much meaningful information on the state of competition in the California market. Nevertheless, in the interest of full disclosure, we have included these results. Note that $\mathrm{MP}(\mathrm{S})$ is significantly larger during the higher demand months of July through September. They are also much higher during the daytime, higher-demand hours than at night.

This fluctuation in the incidence of market power, to coincide with higher demand (and price) hours, is entirely consistent with the nature of competition in the electricity 


\section{Table 4: Actual Price and Estimated Marginal Cost (\$/MWh)}

\begin{tabular}{|c|c|c|c|c|c|c|}
\hline Month & Year & $\begin{array}{c}\text { mean of } \\
\text { actual demand } \\
\text { per hour }\end{array}$ & $\begin{array}{r}\text { mean of } \\
\mathrm{PX} \\
\text { price }\end{array}$ & $\begin{array}{r}\text { mean of } \\
\text { marginal } \\
\text { cost }\end{array}$ & $\begin{array}{r}\text { mean of } \\
\Delta T C\end{array}$ & $\begin{array}{r}\text { aggregate } \\
\frac{\Delta T C}{T C}\end{array}$ \\
\hline June & 1998 & 24852 & 12.09 & 22.99 & -105552 & -0.593 \\
\hline July & 1998 & 29122 & 32.41 & 26.87 & 176664 & 0.280 \\
\hline August & 1998 & 30691 & 39.53 & 27.45 & 342842 & 0.399 \\
\hline September & 1998 & 27526 & 34.01 & 25.64 & 228653 & 0.350 \\
\hline October & 1998 & 24222 & 26.65 & 25.93 & 26231 & 0.073 \\
\hline November & 1998 & 23498 & 25.74 & 27.11 & 897 & 0.003 \\
\hline December & 1998 & 24628 & 29.13 & 25.64 & 72973 & 0.177 \\
\hline January & 1999 & 24013 & 20.96 & 22.71 & -7764 & -0.021 \\
\hline February & 1999 & 24219 & 19.03 & 21.26 & -20137 & -0.061 \\
\hline March & 1999 & 24469 & 18.83 & 20.88 & -17672 & -0.063 \\
\hline April & 1999 & 24166 & 24.01 & 24.17 & 13817 & 0.040 \\
\hline May & 1999 & 24264 & 23.61 & 25.30 & 2425 & 0.007 \\
\hline June & 1999 & 26609 & 23.52 & 25.70 & 27162 & 0.071 \\
\hline July & 1999 & 28878 & 28.92 & 27.30 & 96112 & 0.171 \\
\hline August & 1999 & 29062 & 32.31 & 32.00 & 43384 & 0.070 \\
\hline September & 1999 & 27930 & 33.91 & 30.71 & 93050 & 0.154 \\
\hline
\end{tabular}

industry. During lower demand hours and months, as well as months such as June in which significant hydro energy is available, no single firm can affect prices significantly. During higher demand hours, however, competitive sources of energy begin to reach their capacity limits and the pool of potential competitors for additional supply dwindles. Because of the lack of significant storage capacity and the inelasticity of demand, firms can take advantage of the capacity limits of their competitors during these high demand hours. This is consistent with the effects detected from the oligopoly equilibrium simulations in Borenstein and Bushnell (1999).

For the set of all hours over the entire 16 month period that we study, the $\operatorname{MP}(\mathrm{S})$ is equal to $13.6 \%$, amounting to total payments in excess of competitive levels equal to $\$ 715$ million with a standard error of $\$ 96$ million. Appendix B outlines our procedure for computing this standard error. If we exclude June 1998, $\mathrm{MP}(\mathrm{S})$ is equal to $15.5 \%$ with total payments of $\$ 785$ million in excess of competitive levels with a standard error of $\$ 95$ million. We can convert these magnitudes into average percentage increases over the competitive outcome by dividing the sum of the values of $\Delta T C^{t}$, over the relevant time period, the numerator of $\mathrm{MP}(\mathrm{S})$, by the sum of the values of $\bar{C}^{t}\left[q_{t o t}^{t}-q_{m t}^{t}\right]$, expected costs under the competitive market outcome, over the same time period. For the period 
June 1998 to September 1999, this average markup over the competitive outcome is $15.7 \%$. Excluding the month of June 1998, the average markup over the competitive outcome is $18.3 \%$.

A result that lends further credibility to our measure of market power is that over the period covering January 1999 through May 1999 we find that there was essentially no margin between prices and marginal cost. Computing the value of $\mathrm{MP}(\mathrm{S})$ over this time horizon yields a value approximately equal to zero. As one might expect, during this time period system loads are sufficiently low relative to total capacity available to serve the California market so that competition between generating unit owners is sufficient to cause all firms to bid on average as if they are price-takers in the energy market. In addition, these results provide evidence that significant short-run operating costs are not missing from our cost estimates, because negative or zero margins should not be observed over such an extended period of time.

We explore the relationship between the market power estimates and demand levels a bit further in figures 11 and 12. The horizontal axis of these figures is what we call the "in-state thermal load." It is the system demand minus imports, hydro and must-take power produced in the given hour. The horizontal axis is the ratio $\Delta T C^{t} / T C^{t}$ for that hour. ${ }^{36}$ Figure 10 plots this relationship for all 16 months of the study period. It shows a clearly strong positive relationship between the net (of imports, hydro, and must-take) demand on the system and the degree of market power exercised.

Figure 12 compares the relationship between residual load and price-cost margins for the summers of 1998 and 1999, respectively. In both figures, we have plotted a quadratic fit of the load-margin relationship over both summers. These show that the level of market power, even after adjusting for residual load, was higher during the summer 1998 than 1999. In addition to the structural changes in generation ownership described above, several other factors most likely contributed to the improved state of competition in 1999. These factors include a restructuring of the contracts for providing 'must-run' services under which most generators were operating during 1998 (see Bushnell and Wolak (1999)) and the implementation of a block-forward market by the California Power Exchange, in which the distribution companies were able to contract forward for portions of their purchasing needs.

Yet, a significant change in the market that took place the day after the end of our study period may slow the trend toward more competitive wholesale prices in Califor-

\footnotetext{
36 Negative values of the ratio are set to zero to maintain a reasonable scale for the figure.
} 
nia. On October 1, 1999 the energy price cap in the ISO was raised from $\$ 250 / \mathrm{MWh}$ to $\$ 750 /$ MWh. Shortly thereafter prices reached $\$ 750$ in northern California. Market prices during June and July 2000 often hit these levels, prompting a lowering of the cap. The data necessary to evaluate the extent to which prices exceeded marginal cost during this period were not available at the time of this writing.

It is true that the higher price cap can allow firms to better recoup legitimate scarcity rents when the system is truely short of available capacity. It is important to recognize, however, that the effects we have identified here are not the result of competitive peakload pricing, under which the price should rise during peak demand times to reflect the higher marginal cost of production during those times. Competitive peak-load pricing is manifested in the increased marginal costs we estimate as the ISO load rises (and the fact that our market power measure always takes on a zero or negative value when a simulation indicates that there is insufficient total capacity to meet demand). Those marginal costs reflect the actual level of consumption in each hour and the estimated marginal cost given the available capacity. The ratios we report indicate price increases above the levels that would occur in the course of competitive price responses to peak demands. The results for the winter period also indicate that the non-convexities in producer costs due to various operating constraints are not significantly contributing to our estimates of the price-cost margin.

\section{Conclusions}

Restructuring of electricity industries has been predicated on the belief that competitive wholesale electricity markets can be attained. The debate over whether that assumption is correct and what must be done to ensure competition in electricity generation is ongoing. We have attempted here to make a reliable first estimate of whether and the degree to which California's wholesale electricity market has deviated from the competitive ideal.

Though a great deal of cost data are available for electricity generation units, we still had to make a number of assumptions in order to reach an estimate of the extent of market power in California. In most, though not all, cases, we have made assumptions that, if anything, are likely to produce results indicating less market power than actually exists.

The results indicate that market power in California's wholesale market was a significant factor during the summers of 1998 and 1999, though somewhat less so in 1999. Of course, the market was still very new at these times and changes are occuring in both the production and regulatory arenas that may change the ability of firms to exercise market 
power in the future. Nonetheless, these estimates should serve as a reminder that the problem that was addressed in a purely regulatory framework for most of the 20th century has not completely disappeared with the recent restructuring. These results demonstrate that market power is currently most commonly exercised during peak demand periods, given the current inflexibility of wholesale demand to respond to high hourly spot prices. This underscores the importance of designing wholesale electricity markets that maximize the likelihood that wholesale price signals will be reflected in retail electricity rates.

These estimates demonstrate the degree to which prices exceed system marginal costs, the price level that would occur if all firms behaved as competitive price takers. We have not attempted to assess the profitability of any generation firms selling in California, since such profits are not necessarily an indication of market power, just as the absence of profits is not an indicator of competitive behavior. Under very favorable conditions for electric power supply, such as the high hydro conditions experienced over at least the first half of 1998, firms may have difficulty earning profits whether or not they are able to exercise market power. In all markets with durable assets, such as is the case in this industry, there are likely to be periods of high and low (or negative) profits regardless of the competitiveness of the market. Thus, the profits of generating companies in California during the time period we study provide little information about the competitiveness of this market. ${ }^{37}$

Finally, we want to emphasize again that this study was intended to develop an index of the extent and severity of market power. We consider this to be separable from the important debate over what index levels indicate a need for some form of market intervention. Years of electricity regulation confirmed the belief that government intervention can be costly and can result in tremendously inefficient production. The balancing of the costs and benefits of such intervention will require a great deal more study in this industry as restructuring proceeds.

37 It is also worth noting that we have analyzed only the energy markets in California. Most generation units are eligible to earn additional revenues under reliability must-run contracts and from the sale of ancillary services. During the summer of 1998 RMR costs and ancillary services costs were significantly higher than were expected at the time the California market began. 


\section{References}

Andrews, D.W.K. (1991), "Heteroskedasticity and Autocorrelation Consistent Covariance Matrix Estimation," Econometrica, 59, pp. 817-858.

Bohn, R., Klevorick, A., and Stalon, C. (1999). "Second Report on Market Issues in the California Power Exchange Energy Markets." Available at www.calpx.com.

Borenstein, S. and Bushnell, J.B. (1999). "An Empirical Analysis of the Potential for Market Power in California's Electricity Market." Journal of Industrial Economics, 47(September 1999).

Borenstein, S., Bushnell, J.B., and S. Stoft (2000). "The Competitive Effects of Transmission Capacity in a Deregulated Electricity Market." RAND Journal of Economics, 31(Summer 2000).

Borenstein, S., Bushnell, J.B., and C. Knittel (1999). "Market Power in Electricity Markets: Beyond Concentration Measures," The Energy Journal, 20(4,1999).

Borenstein, S., Bushnell, J.B., C. Knittel, and C. Wolfram (2000). "Price Convergence in the California Electricity Markets," mimeo, University of California Energy Institute.

Bushnell, J.B. (1998). "Water and Power: Hydroelectric Resources in the Era of Competition in the Western U.S.," POWER working paper PWP-056, University of California Energy Institute.

Bushnell, J.B. (1999). "Transmission Rights and Market Power," The Electricity Journal, 12(8), pp. $77-85$.

Bushnell, J.B. and S.S. Oren (1997). "Transmission Pricing in California's Proposed Electricity Market." Utilities Policy, 6(3), pp. 237-244.

Bushnell, J.B. and F.A. Wolak (1999). "Regulation and the Leverage of Local Market Power: Reliability Must-Run Contracts in the California Electricity Market." POWER Working Paper PWP-070, University of California Energy Institute.

California Energy Commission (CEC, 1995). 1994 Electricity Report. Data appendices. Sacramento, CA.

Cardell, J.B., C.C. Hitt, and W.W. Hogan (1997). "Market Power and Strategic Interaction in Electricity Networks." Resources and Energy Economics. 19(1-2), pp. 109-138.

Green, R.J., and D.M. Newbery (1992). "Competition in the British Electricity Spot Market." Journal of Political Economy. 100(5), pp. 929-953.

Joskow, P.L. and J. Tirole (2000). "Transmission Rights and Market Power on Electric Power Networks." RAND Journal of Economics, Forthcoming.

Kahn, E., Bailey, S., and Pando, L. (1996), "Simulating Electricity Restructuring in California: Interactions with the Regional Market," Resources and Energy Economics, 19(1-2).

Newey, W.K., K.D. West (1987), "A Simple, Positive Semi-Definite, Heteroskedasticity and Autocorrelation Consistent Covariance Matrix," Econometrica . 55, pp. 703-708.

Oren, S.S. (1997). "Economic Inefficiency of Passive Transmission Rights in Congested Electricity Systems with Competitive Generation." The Energy Journal. 18, (1), pp. 63-83. 
Pando, L. (1995). Testimony and Workpapers in Southern California Gas Company CPUC Application No. 95-06-002.

Panzar, J., (1976). "A Neoclassical Approach to Peak-Load Pricing," Bell Journal of Economics. 7(2), pp. 521-530.

Schmalensee, R. and B. W. Golub (1985). "Estimating effective concentration in deregulated wholesale electricity markets," RAND Journal of Economics. 15(1), pp. 12-26.

Wolak, F.A. and R.H. Patrick (1996). "The Impact of Market Rules and Market Structure on the Price Determination Process in the England and Wales Electricity Market," POWER working paper PWP-047, University of California Energy Institute.

Wolak, F.A. (1999). "An Empirical Analysis of the Impact of Hedge Contracts on Bidding Behavior in a Competitive Electricity Market," mimeo, Stanford University.

Wolak, F.A., Nordhaus, R., and C. Shapiro (1998). "Preliminary Report on the Operation of the Ancillary Services Markets of the California Independent System Operator (ISO)." Avaliable at www.ucei.berkeley.edu/ucei/filings.html

Wolfram, C.D. (1998), "Strategic Bidding in a MultiUnit Auction: An Empirical Analysis of Bids to Supply Electricity in England and Wales," RAND Journal of Economics, 29(4), pp. 703-725.

Wolfram, C.D. (1999), "Measuring Duopoly Power in the British Electricity Spot Market," American Economic Review, 89(4), pp.805-826. 


\section{Appendix A: Data Sources}

\section{Thermal Generation Data}

Heat rates for thermal generation units that were not must-take and were located within the ISO control area are primarily taken from the California Energy Commission's dataset on WSCC generation for use with General Electric's MAPS multi-area production cost model. This is the dataset used in Borenstein and Bushnell (1999). Some unit heat rates were taken from the data set used by Southern California Gas Company in its 1995 performance-based ratemaking simulation studies (Pando, 1995). This dataset was also used by Kahn, et. al (1996) in their simulation analysis of the WSCC.

An overwhelming share of California thermal generation is fueled by natural gas. For the time period studied, we used weekly average natural gas spot prices reported by Natural Gas Intelligence at PG\&E citygate and the California-Arizona border. The former were used for generation units north of path 15 while the latter were used for generation units in the south. Both sets of prices were adjusted by the distribution rates of the gas utility serving each generator.

A small number of California generators use either fuel oil or Jet fuel as their primary or secondary fuel. Jet fuel and fuel oil prices were aggregated over the four months and across the ISO control area. The price of number 2 fuel oil was assumed to be $\$ 2.98 / \mathrm{Mbtu}$ during the time period of this study. These figures are the year-to-date average costs of each fuel delivered to California electricity producers, taken from the Energy Information Administration's Electric Power Monthly. The price of jet fuel was taken from the MAPS dataset and assumed to be $\$ 3.29 / \mathrm{Mbtu}$.

Unit forced outage factors are taken from the National Electricity Reliability Council's (NERC) 1993-1997 Generating Unit Statistical Brochure, which reports aggregate generation unit performance data by fuel type and nameplate capacity. The forced outage factor that we used for our Monte-Carlo simulations were derived from the NERC reported unit Equivalent Availability Factors (EAF) and unit Scheduled Outage Factors (SOF). The former gives the fraction of total hours in which a generation unit was available, including an adjustment for partial outages, while the latter gives the fraction of hours in which each unit was unavailable due to scheduled maintenance procedures. Our derived forced outage factor, which reflects the fraction of time a unit was not available for production for unplanned reasons, was

$$
F O F=1-\frac{E A F}{1-S O F}
$$




\section{Demand and Generation Output Data}

Total ISO quantity for every hour is based upon the ISO's real-time metered generation and is taken from ISO settlement data. The output of must-take, hydro, and geothermal generation for each hour is also taken from these data. Imports are calculated from the net of real-time metered imports and exports aggregated over all transmission interties connecting the ISO's control area with neighboring control areas. The Mohave generation plant, although located outside of California, appears in metered data as musttake generating facility and not as an import. Production from all other generation units owned by SCE, but located outside of California, appear as imports in the settlement data. 


\section{Appendix B: Calculation of Standard Error for $\Delta T C(S)$}

The observed PX price in hour i and day $\mathrm{d}, \hat{p}_{p x}^{i d}$, depends on a single realization of the joint distribution of generation unit-level outages during that hour. A different realization of unit-level outages for that hour could result in a very different observed PX price for that hour. Because we do not know the precise nature of the competitive interaction among market participants, specifically the bidding strategies of both generators and loads which gave rise to the observed market-clearing PX price, we are unable to replicate the actual price-setting process for a large number of draws from the joint distribution of unit-level outages in order to compute the expected value of the PX price, $E\left(\hat{p}_{p x}^{t}\right)$. In constrast, we can compute the perfectly competitive market counter-factual equilibrium because it entails the assumption of marginal cost bidding by all in-state fossil generation unit-owners. This allows us to compute the realized value of the marginal cost of the highest cost unit operating in that hour for a large number of draws from the joint distribution of unit-level outages and therefore compute the expected value of this marginal cost to an arbitrarily degree of precision for each hour. We found that the 100 realizations from the joint distribution of unit-level outages led to a very precise estimates of this expected marginal cost for each hour. Consequently, the remaining source of uncertainty in $\Delta T C(S)$, the total cost difference due to deviations from competitive prices over time period $\mathrm{S}$, that our standard error estimate accounts for is the uncertainty in PX prices caused by forced outages.

In constructing the standard error estimate for $\Delta T C$, we account for arbitrary correlation in $\left[\hat{p}^{i d}-\bar{C}^{i d}\right]$ across the 24 hours of the day and general forms of autocorrelation in these 24 prices across days. We can write the total cost difference due to deviations from competitive prices over time period $\mathrm{S}$ as,

$$
\Delta T C(S)=\sum_{d \in S} \sum_{i=1}^{24}\left[\hat{p}_{p x}^{i d}-\bar{C}^{i d}\right]\left[q_{t o t}^{i d}-q^{i d}\right]=\sum_{d \in S} \sum_{i=1}^{24} m k u p^{i d} q n^{i d},
$$

where $q n^{i d}=\left[q_{t o t}^{i d}-q^{i d}\right]$ and $m k u p^{i d}=\left[\hat{p}^{i d}-\bar{C}^{i d}\right]$. This expression can be re-written as:

$$
\Delta T C(S)=\sum_{d \in S} \sum_{i=1}^{24} E\left(m k u p^{i d}\right) q n^{i d}+\sum_{d \in S} \sum_{i=1}^{24} \epsilon^{i d} q n^{i d},
$$

where $\epsilon^{i d}=m k u p^{i d}-E\left(m k u p^{i d}\right)$ and $E($.$) denotes the expectation taken with respect$ to the joint distribution of unit-level forced outages. Therefore the variance of $\Delta T C(S)$ can be written as:

$$
\operatorname{Var}(\Delta T C(S))=\operatorname{Var}\left(\sum_{d \in S} \sum_{i=1}^{24} \epsilon^{i d} q n^{i d}\right)=\operatorname{Var}\left(\sum_{d \in S} Z_{d}\right),
$$


where $Z_{d}=\sum_{i=1}^{24} \epsilon^{i d} q n^{i d}$. Under suitable regularity conditions on the sequence $Z_{d}$, for example those assumed in Newey and West (1987) or Andrews (1991), we can show that $(D A Y(S))^{-1 / 2}\left(\sum_{d \in S} Z_{d}\right)$ converges in distribution to a $\mathrm{N}(0, \mathrm{~V})$ random variable, as $\mathrm{DAY}(\mathrm{S})$ tends to infinity, where $\operatorname{DAY}(\mathrm{S})$ equals the number of days in time period $\mathrm{S}$. A consistent estimate of $\mathrm{V}$ can be constructed as follows:

$$
\hat{V}=g_{Z}(0)+2 \sum_{\tau=1}^{q} k(\tau /(q+1)) g_{Z}(\tau)
$$

where $g_{Z}(0)=1 / D A Y(S) \sum_{d=1}^{D A Y(S)}\left(Z_{d}\right)^{2}, g_{Z}(\tau)=1 / D A Y(S) \sum_{d=\tau+1}^{D A Y(S)}\left(Z_{d} Z_{d}-\tau\right)$, and $\mathrm{k}(\mathrm{t})$ is a weight function satisfying restrictions given in Andrews (1991). Using this asymptotic distribution result, an estimate of the variance of $\Delta T C(S)$ is $(D A Y(S) \hat{V})$, which implies a standard error of $(D A Y(S) \hat{V})^{1 / 2}$.

To operationalize this procedure we need to construct an estimate of the unobservable, $\epsilon^{i d}$, the difference between $m k u p^{i d}$, and its expectation. As discussed above, in order to compute the exact expectation of $m k u p^{i d}$ we would need to know how all market participants bid into the PX (and other markets) as a function of current conditions in the market (system load and local reliability energy levels) and the realization of unit-level outages. Because we do not know the bidding strategies of even a single market participant and we do not observe actual generation unit-level outages during our sample period, a reduced form approach to construct the estimate of $E\left(m k u p^{i d}\right)$ is necessary to compute an estimate of $\epsilon^{i d}$. We use a linear predictor of $m k u p^{i d}$ constructed using hour-of-day, day-of-the-week, and month-of-sample period dummies, along with the level and square of both the forecast ISO load and day-ahead total RMR requirements for that hour of the day. Our estimate of $\epsilon^{i d}$ is the residual from the regression of $m k u p^{i d}$ on these variables for all hours in our sample period. For same reason that the squared difference between a random variable and its conditional expectation is always less than the squared difference between that random variable and its best linear predictor using those same conditioning variables, the variance of our estimate of $\epsilon^{i d}$ should be larger than the true variance of $\epsilon^{i d}$. Consequently, we view our standard error as a very conservative estimate of the uncertainty in $\Delta T C(S)$ due to unobservable forced outages on realizations of the PX price.

Applying this procedure with the Barlett kernel, $k(s /(q+1))=s /(q+1)$, for a value of q equal to 40 yields a standard error for $\Delta T C(S)$ for our entire sample period of $\$ 96$ million. This should be compared to the value of $\Delta T C(S)$ for this period of $\$ 715$ million. Repeating this entire procedure for the period July 1999 to September 1999 yields a standard error $\$ 95$ million for $\Delta T C(S)$ of $\$ 785$ million. These values of $\Delta T C(S)$ and the associated standard error estimates reinforce our conclusion that significant market 
power has been exercised in the California electricity market during the period June 1998 to September 1999. 


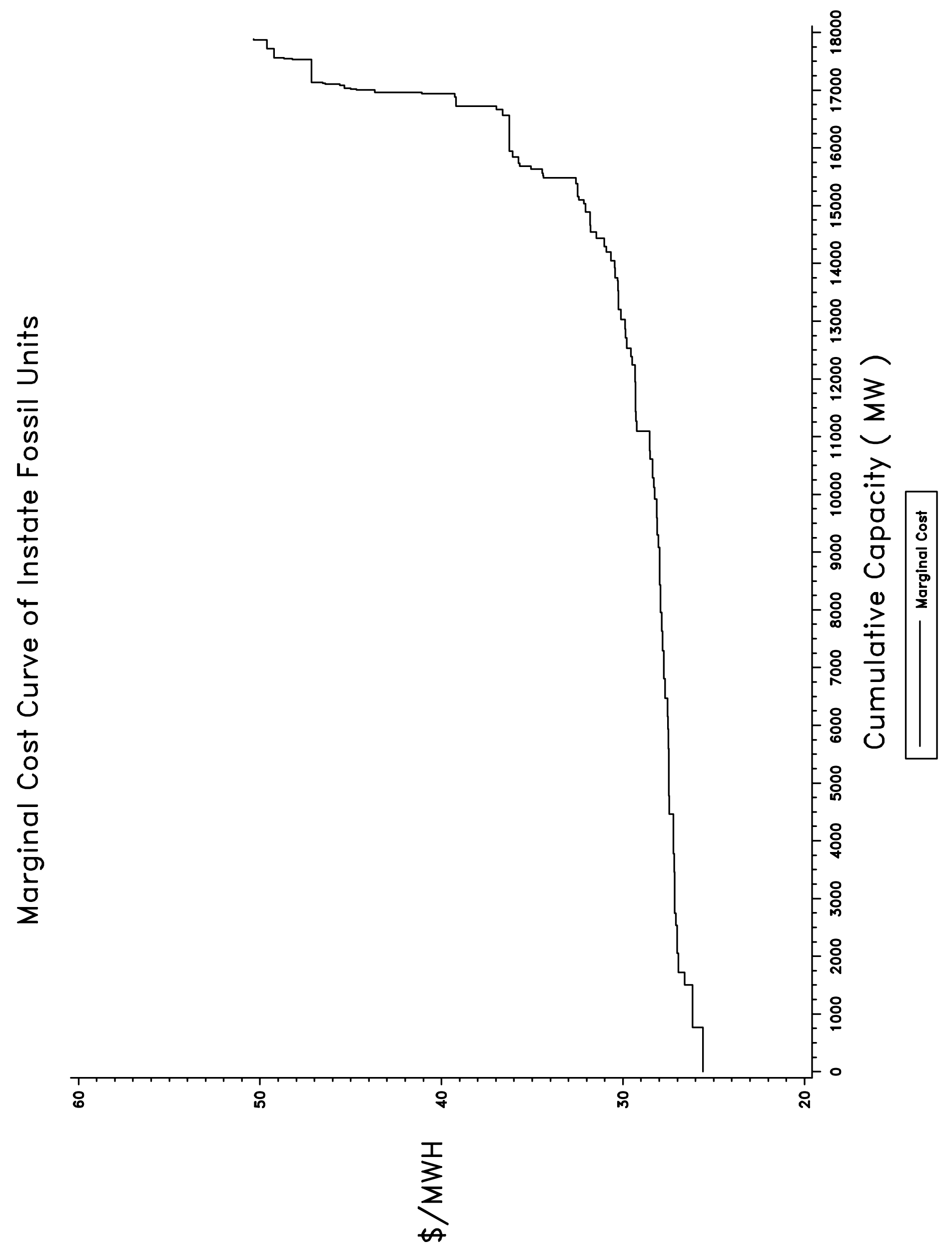




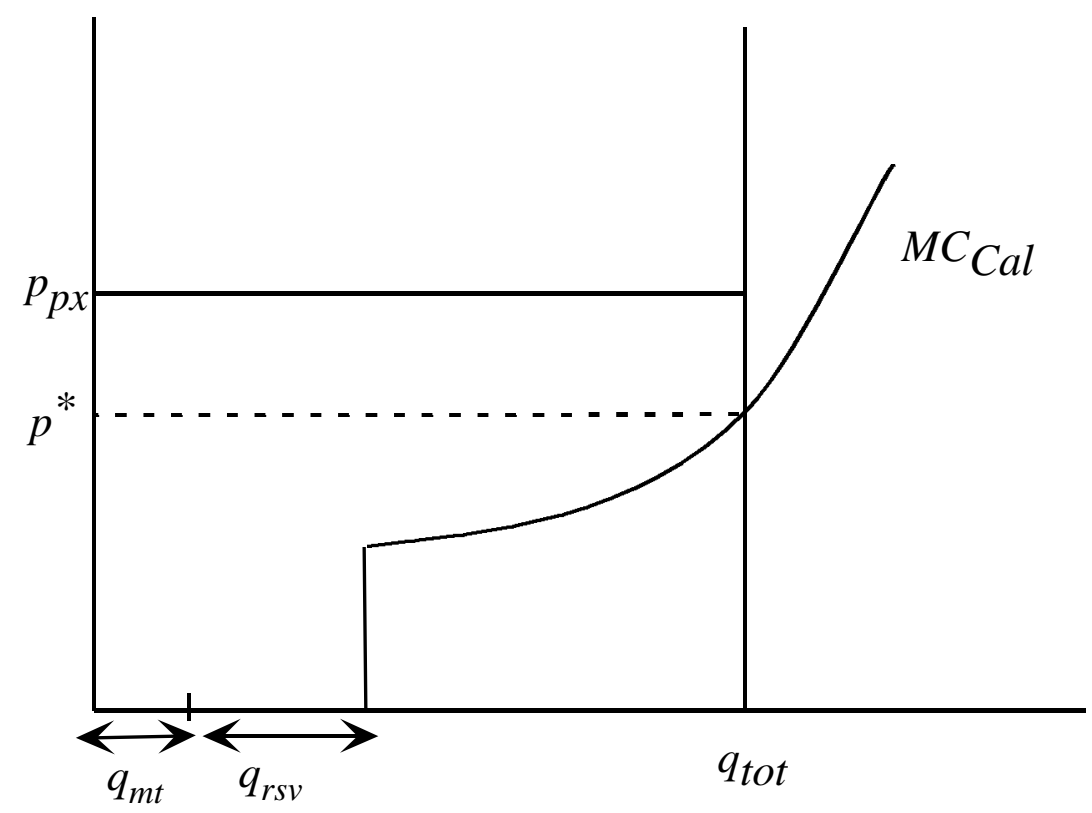

Figure 2: Treatment of must-take and reservoir energy sources

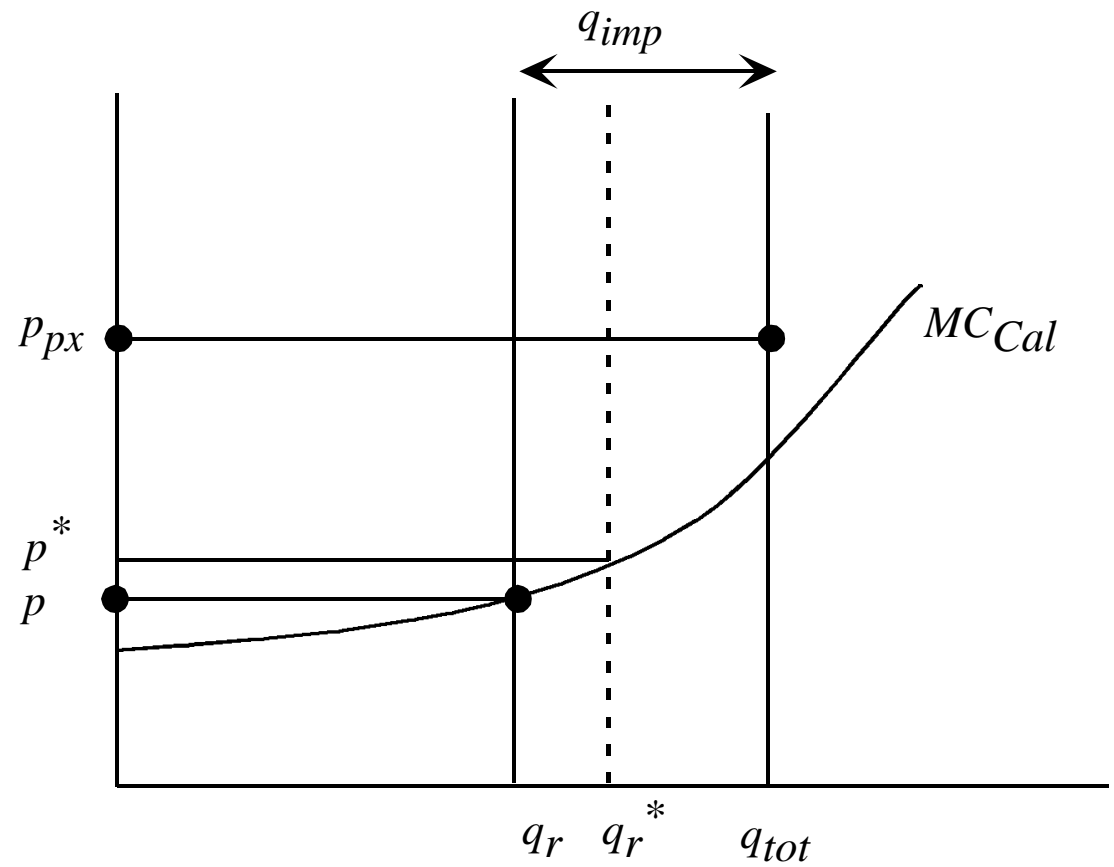

Figure 3: Bounding the impact of imports on marginal cost 
PX Price and Predicted Marginal Cost: July 1998

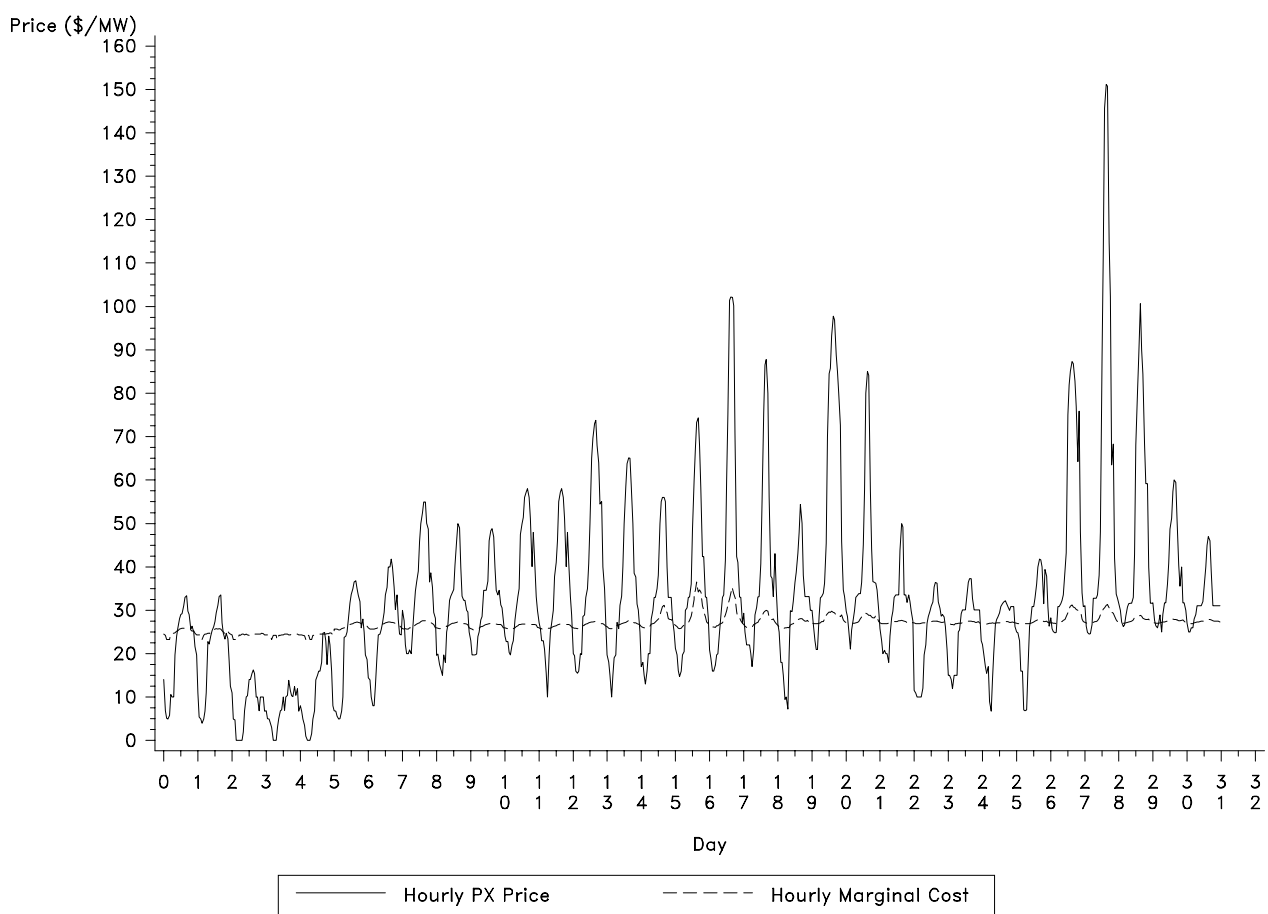

Figure 4

PX Price and Predicted Marginal Cost: August 1998

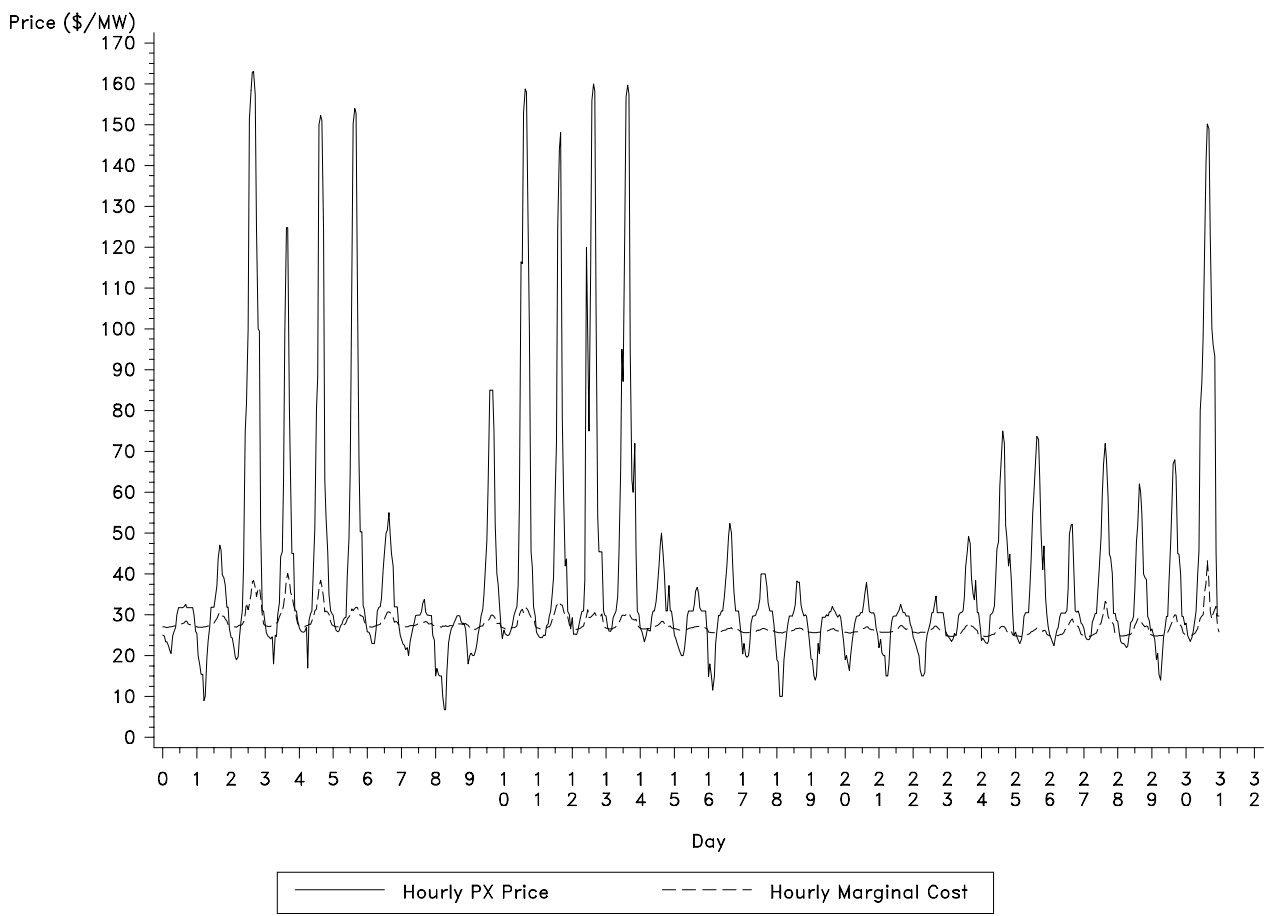

Figure 5 
PX Price and Predicted Marginal Cost: September 1998

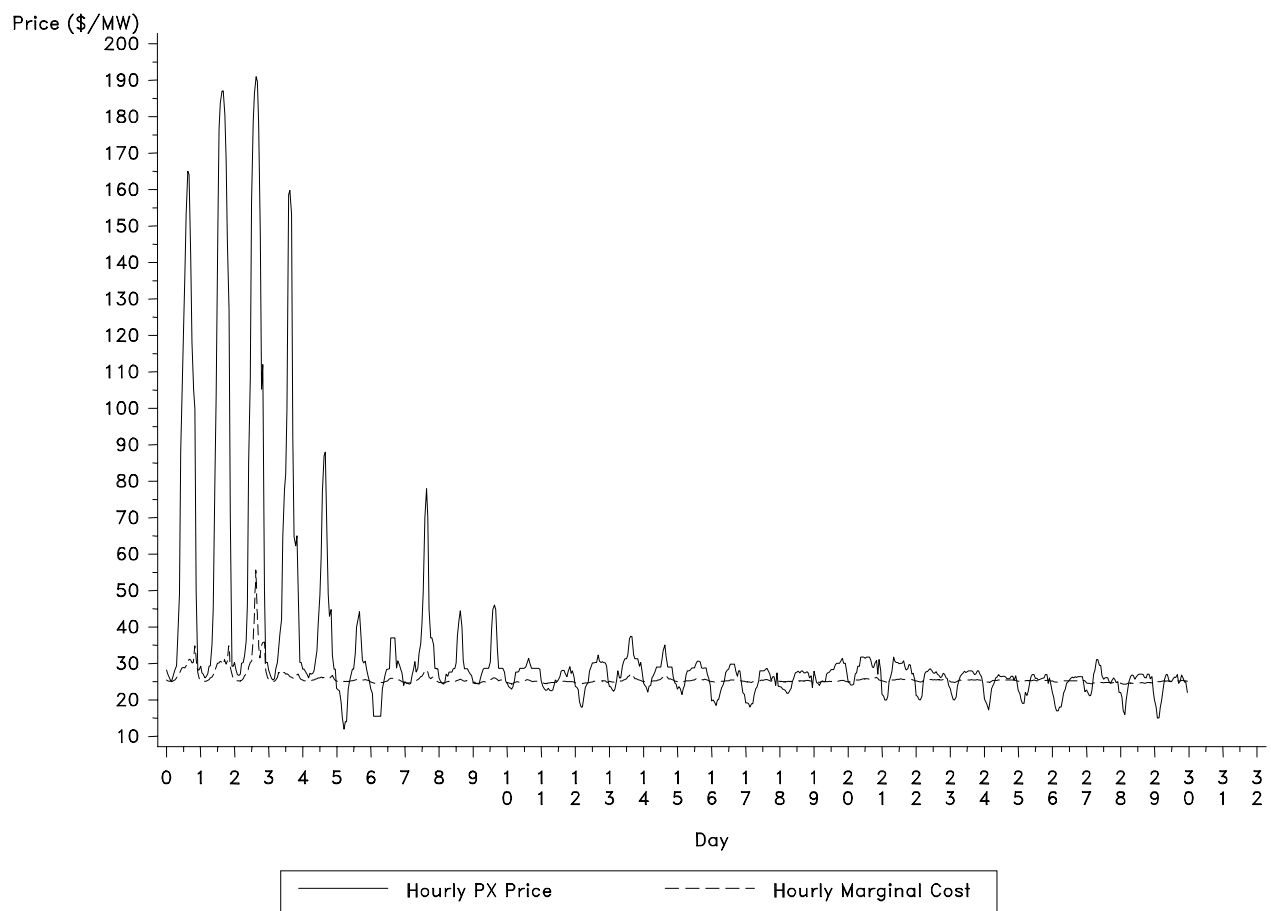

Figure 6

PX Price and Predicted Marginal Cost: January 1999

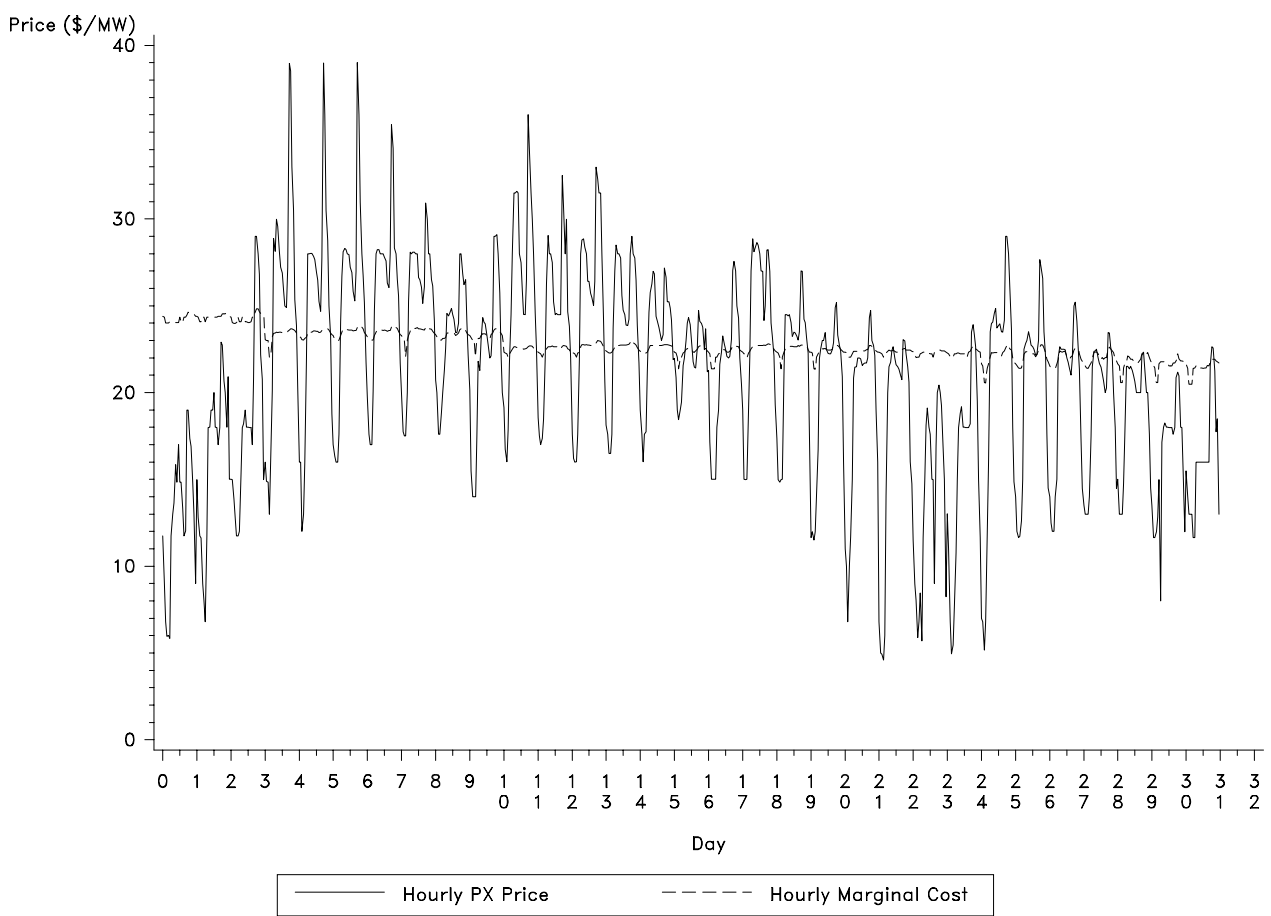

Figure 7 
PX Price and Predicted Marginal Cost: July 1999

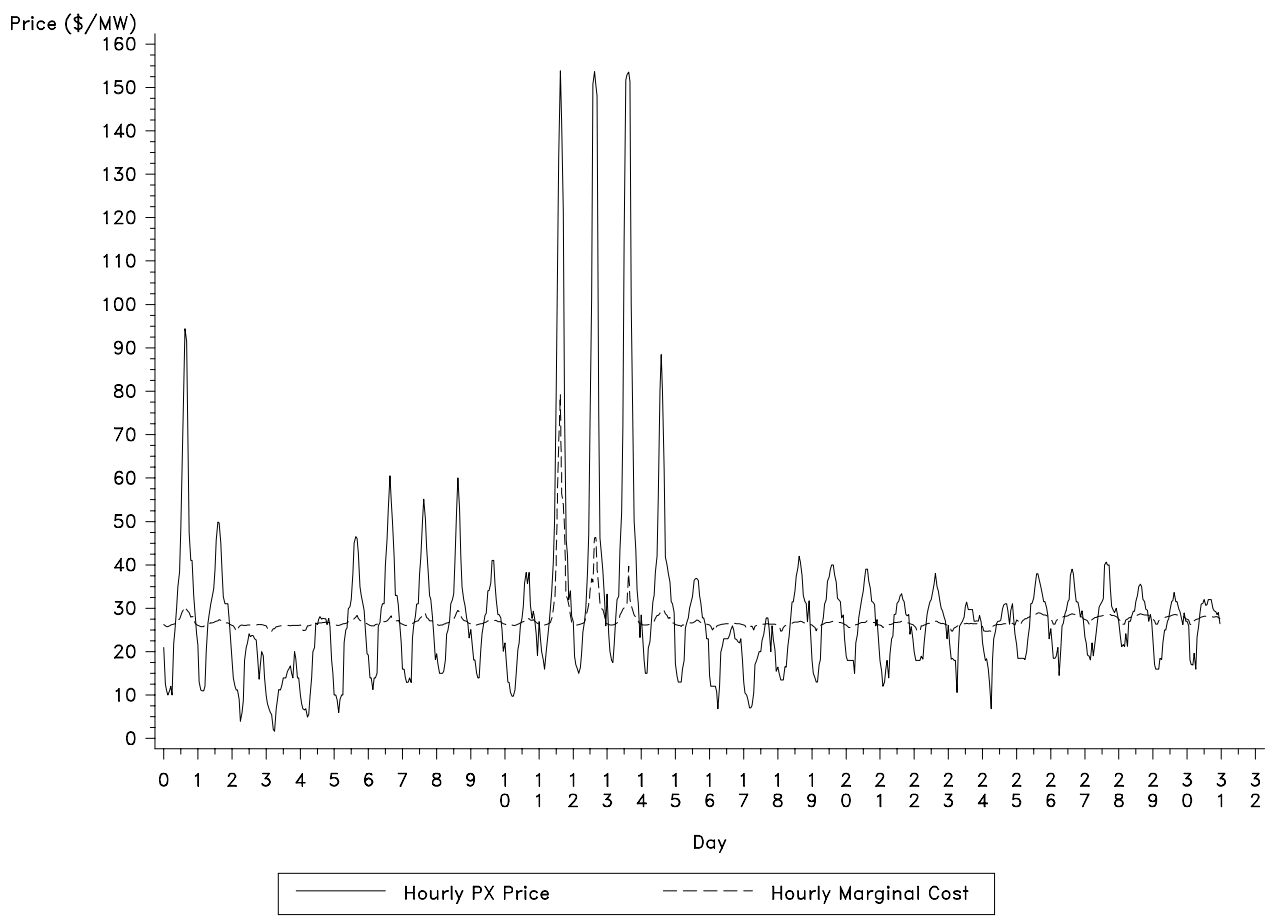

Figure 8

PX Price and Predicted Marginal Cost: August 1999

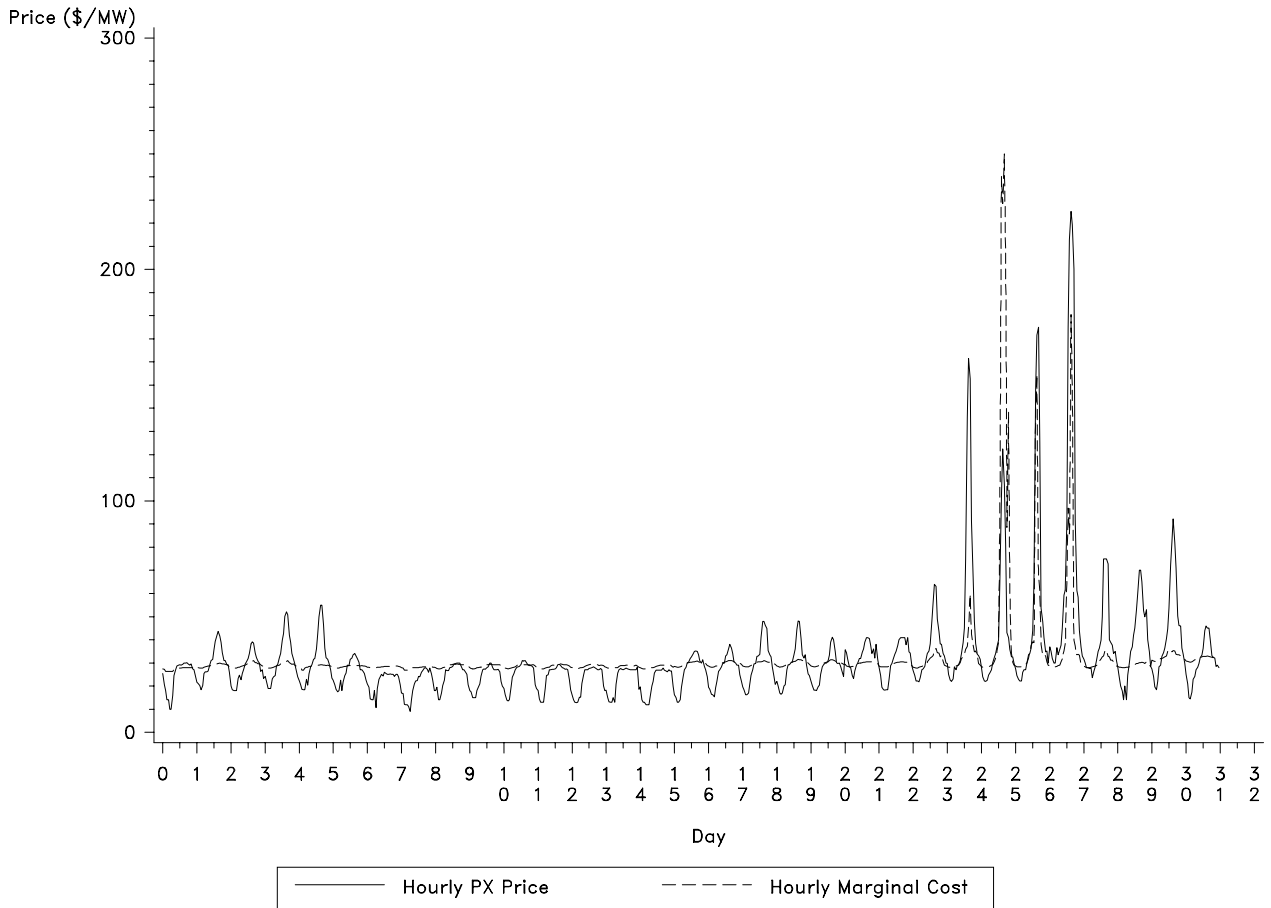

Figure 9 
PX Price and Predicted Marginal Cost: September 1999

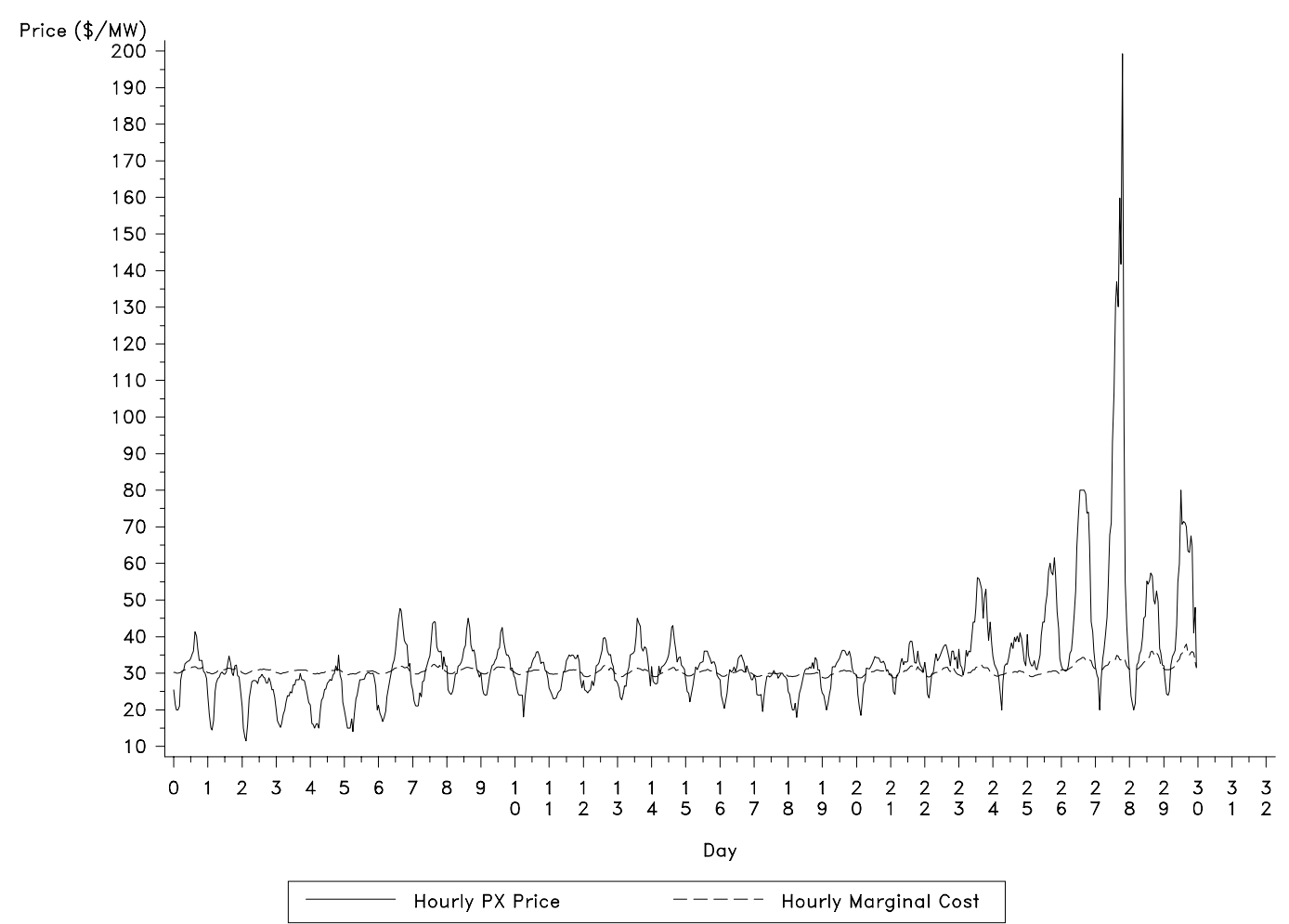

Figure 10 

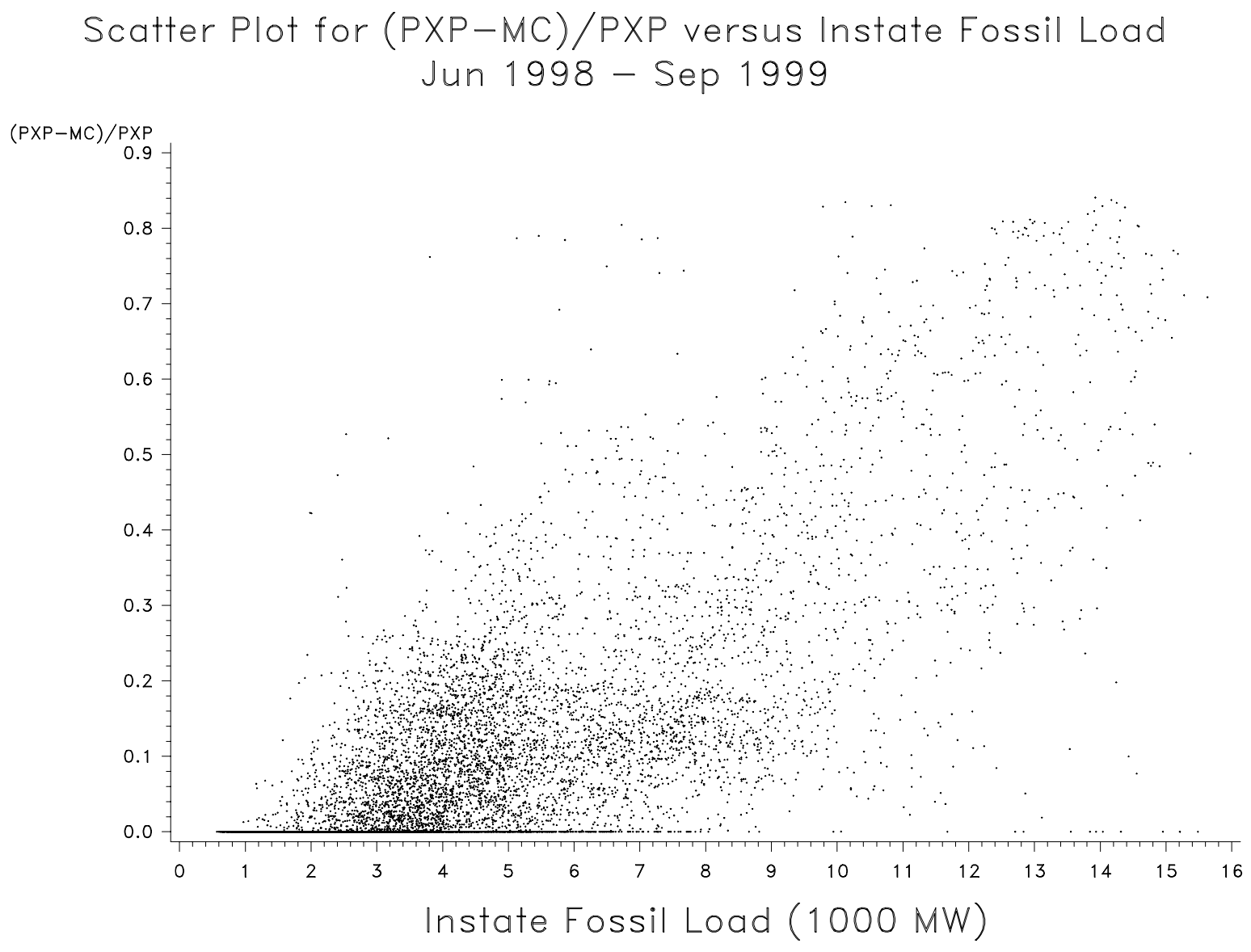

Figure 11 


\section{Scatter Plot for (PXP-MC)/PXP versus Instate Fossil Load Summer 1998 and 1999}

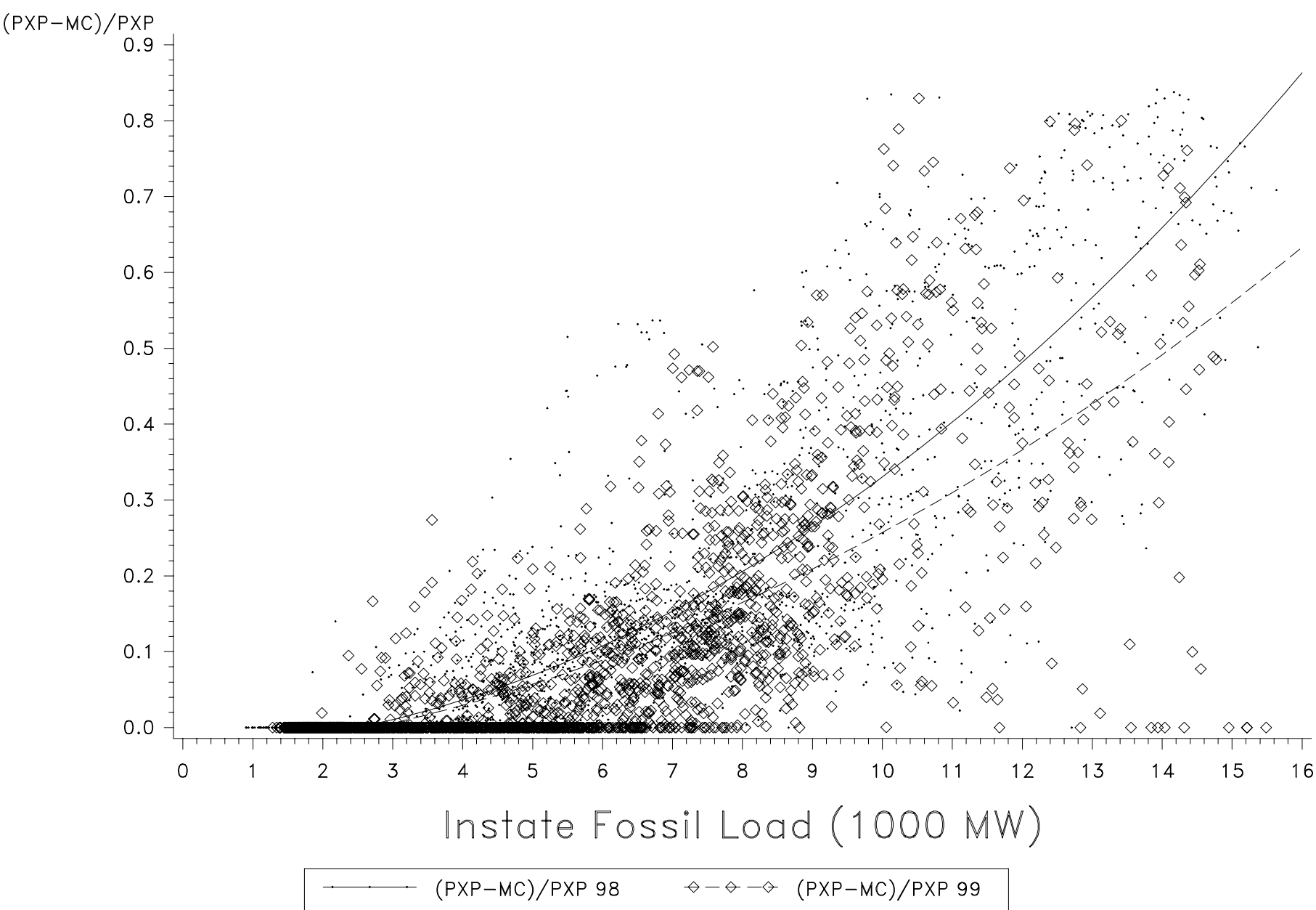

Figure 12: Lerner Indices for Summer 1998 and 1999 